\title{
Article
}

\section{Paranormal belief and errors of probabilistic reasoning: The role of constituent conditional relatedness in believers' susceptibility to the conjunction fallacy}

Rogers, Paul, Fisk, John and Lowrie, Emma Louise

Available at http://clok.uclan.ac.uk/20496/

Rogers, Paul, Fisk, John ORCID: 0000-0002-2981-0870 and Lowrie, Emma Louise (2017) Paranormal belief and errors of probabilistic reasoning: The role of constituent conditional relatedness in believers' susceptibility to the conjunction fallacy. Consciousness and Cognition, 56 . pp. 13-29. ISSN 10538100

It is advisable to refer to the publisher's version if you intend to cite from the work. http://dx.doi.org/10.1016/j.concog.2017.09.010

For more information about UCLan's research in this area go to

http://www.uclan.ac.uk/researchgroups/ and search for < name of research Group>.

For information about Research generally at UCLan please go to http://www.uclan.ac.uk/research/

All outputs in CLoK are protected by Intellectual Property Rights law, including Copyright law. Copyright, IPR and Moral Rights for the works on this site are retained by the individual authors and/or other copyright owners. Terms and conditions for use of this material are defined in the policies page. 
Paranormal belief and errors of probabilistic reasoning: The role of constituent conditional relatedness in believers' susceptibility to the conjunction fallacy.

Paul Rogers $\mathrm{PhD}^{\mathrm{a}}$., John E. Fisk $\mathrm{PhD}^{\mathrm{b}}$ and Emma Lowrie ${ }^{\mathrm{b}}$

aAnomalistic Psychology Research Unit, Department of Psychology, Goldsmith's College, University of London, New Cross, London SE14 8NW, UK.

${ }^{\mathrm{b}} \mathrm{School}$ of Psychology, University of Central Lancashire, Preston, Lancashire, PR1 2HE, UK

Please direct correspondence to: Dr Paul Rogers via email at progers1966@gmail.com 


\section{Highlights}

1. belief in psychokinesis predicted more conjunction errors (CEs)

2. belief in extrasensory perception and life after death did not predict CEs

3. more CEs were made for conditionally related (verses unrelated) constituent events

4. higher estimates of the more surprising constituent predicted fewer CEs

5. generally less qualified individuals also made more CEs 


\begin{abstract}
The present study examines the extent to which stronger belief in either extrasensory perception, psychokinesis or life-after-death is associated with a proneness to making conjunction errors (CEs). One hundred and sixty members of the UK public read eight hypothetical scenarios and for each estimated the likelihood that two constituent events alone plus their conjunction would occur. The impact of paranormal belief plus constituents' conditional relatedness type, estimates of the subjectively less likely and more likely constituents plus relevant interaction terms tested via three Generalized Linear Mixed Models. General qualification levels were controlled for. As expected, stronger PK beliefs and depiction of a positively conditionally related (verses conditionally unrelated) constituent pairs predicted higher CE generation. ESP and LAD beliefs had no impact with, surprisingly, higher estimates of the less likely constituent predicting fewer - not more - CEs. Theoretical implications, methodological issues and ideas for future research are discussed.
\end{abstract}




\section{Introduction}

The veracity of reported paranormal experiences remains a hotly debated topic (e.g., Krippner \& Friedman, 2010) which, if ever verified, would have profound implications for the so-called "hard problem" of consciousness research; how physical brain processes give rise to subjective experiences. Extrasensory perception (ESP; defined as the alleged ability to obtain information without recourse to the known senses or through logical inference), psychokinesis (PK; the alleged ability to influence physical systems directly through mental processes) and life after death (LAD: the notion that some disembodied aspect of human personality or consciousness survives bodily death, at least for a time) all challenge preexisting doctrines in which mental states are either dismissed (materialism) else seen to be a mere by-product of neurological processes (epiphenomenalism). If consciousness can survive bodily death then, by definition, a physical brain is not required for subjective mental states to be experienced. Regardless of their veracity ostensibly paranormal experiences tend to have significant impact on a person's worldview and self-concept (Cardeña, Lynn, \& Krippner, 2014).

Skeptics - and in particular anomalistic psychologists - try to understand paranormal beliefs and experiences by recourse to known physical and/or psychological processes. Factors known to underlie at least some types of paranormal endorsement are both varied and complex (French \& Stone, 2014; Irwin, 2009), and presently include demographic background (e.g., gender, ethnicity); facets of personality (e.g., openness to experiences, fantasy proneness) and individual differences (e.g., scientific education, religiosity); psychobiological composition (e.g., temporal lobe liability, hemispheric dominance); sociocultural influence (e.g., from peers, the media); developmental variation (e.g., childhood trauma, propensity for magical thinking); innate evolutionary processes (e.g., anthropomorphism, agency misperceptions); and finally, both clinical and sub-clinical 
psychopathology (e.g., neuroticism, schizotypy, dissociativity, psychosis). To date, there is much evidence to suggest believers are prone to a variety of cognitive "deficits" (Irwin, 2009), arguably the most robust of which relates to errors of probabilistic reasoning (for a review see Rogers, 2015).

Whilst most people are poor intuitive statisticians (Diaconis \& Mosteller, 1989) this seems especially true of paranormal believers (for a review see Rogers, 2014). For example, it is often claimed paranormal believers "look beyond chance" to causally explain what are essentially chance outcomes (misattribution hypothesis; Wiseman \& Watt, 2006). According to Bressan (2002) paranormal believers possess a comparatively lax internal representation of what constitutes randomness and as such, usually require less objective evidence of relatedness before they will misperceive a subjectively meaningful - hence causal relationship onto otherwise unrelated events; a process Shermer (2011) has termed “patternicity". Believers' proneness to patternicity is associated with either left visual field/ right hemisphere dominance (e.g., Pizzagalli, Lehmann \& Brugger, 2001) else right hemisphere overactivation (e.g., Brugger, Regard, Landis, Cook, Krebs, \& Niederberger, 1993) and, in turn, appears unduly influenced by extraneous factors such as the “observability” of potential causes (Bressan, 2002; although see Rogers, Qualter \& Wood, 2016). As Rogers (2015) asserts, it seems paranormal believers' LVF/RH dominance and/or $\mathrm{RH}$ overactivation leads them to misperceive random events as being (causally) connected in some a meaningful way.

Such misattributions of randomness seem relevant to believers' susceptibility to a more specific bias the so-called conjunction fallacy; the tendency to misjudge independent yet cooccurring (conjunctive) events as being more likely than either constituent event alone (Tversky \& Kahneman, 1982; 1983; see also Fisk, 2017). When thinking about a long-lost friend (constituent 1) is quickly followed, for no observable reason, by the same friend 
unexpectedly telephoning (constituent 2), many people will judge the co-occurrence of these two events (thinking about the friend and then the friend telephoning) more likely than either singular constituent event alone (cf. Rhine-Feather \& Schmicker, 2005). Such conjunctions are reminiscent of reported paranormal experiences such as extrasensory perceptions and thus should be more pronounced in those with stronger paranormal beliefs.

\subsection{Paranormal Belief and the Conjunction Fallacy}

A number of studies suggest adult paranormal belief is associated with more conjunctive errors (CEs) regardless of whether events are depicted within an ostensibly paranormal or clearly non-paranormal context, the implication being that believers are especially prone to a context-neutral or generic conjunction fallacy (Brotherton \& French, 2014; Dagnall, Drinkwater, Denovan, Parker \& Rowley, 2016; Prike, Arnold \& Williamson, 2017; Rogers, Davis \& Fisk, 2009; Rogers, Fisk \& Lowrie, 2016; Rogers, Fisk \& Wiltshire, 2011). Other work has found no such relationship (Dagnall, Denovan, Drinkwater, Parker, \& Clough, 2016; Dagnall, Drinkwater, Parker \& Rowley, 2014; Dagnall, Parker \& Munley, 2007) with Dagnall et al. (2014) claiming believers' are susceptible only to misperceiving randomness ${ }^{1}$.

In the aforementioned study, Rogers et al. (2011) explored believers' fallacy proneness further by testing belief-based differences in likelihood estimates relating to each constituent

\footnotetext{
${ }^{1}$ It should be noted that a number of studies have examined confirmatory and other the reasoning biases inherent in paranormal scepticism. Koehler (1993), for instance, found scientists and other professional sceptics judged the relevance, methodological rigour and presentational quality of research to be higher in studies where results were consistent with (confirmed) their prior belief concerning the veracity of extrasensory perception (ESP), with few recognising their assessment of study quality was influenced by study outcome. Roe (1999) reports similar belief-congruency biases amongst undergraduates classified as believers or disbelievers according to their score on a popular paranormal belief scale (one standard deviation above verses below the mean respectively). More recently, Irwin (2015) employed a task - the viewing of seemingly genuine photographic evidence of self-levitation - specifically designed to evoke a novel paranormal belief/disbelief in real time and found the intensity of newly evoked disbeliefs correlated with a preference for rational-analytic thinking whereas newly evoked beliefs, by comparison, did not. According to Irwin, disbelievers were more inclined to adopt analytic-rational thinking style "as a matter of habit" (p. 137) and the implication being that traditional paranormal belief measures might obscure certain cognitive processes associated only with paranormal scepticism. However, in follow-up work Irwin, Dagnall and Drinkwater (2017) found correlations between paranormal belief and cognitive measures such as thinking style, aberrant salience and emotion-based reasoning were, in absolute terms, just as strong for believers as they were for skeptics leading these authors to conclude paranormal belief and skepticism $d o$ lie on the same unidimensional continuum.
} 
event. Contrary to expectations, paranormal believers deemed the two singular constituents just as likely as did paranormal skeptics. Based on the tacit assumption that constituent and conjunctive events are linearly related, Rogers et al. (2011) also explored belief-based differences in the perceived strength of constituent-conjunction relationships. Such a relationship is indicated by the homogeneity of regression slope between estimates of (a) the subjectively less likely (LL) constituent ${ }^{2}$ and (b) the conjunctive term. No such differences emerged, with the perceived strength of constituent-conjunction relationships unaffected by paranormal belief status.

Despite these negative findings, other research - outside the realm of adult paranormality suggests that the perceived conditional relatedness of constituent pairs will sometimes impact on $\mathrm{CE}$ generation. It is to this literature that discussion now turns.

\subsection{The Conditional Relatedness of Constituent Events}

According to Tversky and Kahneman (1983) the conjunction fallacy usually reflects implicit knowledge of category norms. In such cases, "representative conjunction errors" arise whenever two events (A and B) differ in the extent to which they resemble some internalized model (M) of a target person/event. Representative CEs within this $M \rightarrow A$ paradigm are common and mostly generated by likely/unlikely (L/U) constituent pairs. In such cases, the more representative (likely) constituent is believed to be far more influential in shaping conjunctive probability estimates. Tversky and Kahneman's (1982; 1983) now classic "Linda problem" is often cited as a good illustration of this model ${ }^{3}$.

\footnotetext{
2 The subjectively less likely (LL) constituent event is itself defined by one of two ways. Assuming estimates of the first constituent exceed those of the second $[p(\mathrm{~A})>\mathrm{p}(\mathrm{B})]$ then, for conditionally unrelated constituents LL reflects whichever of the two singular constituents is assigned the lower probability value, in this case $p(\mathrm{~B})$. However, when constituents are conditionally positively related, LL may sometimes be based on the conditional event $p(\mathrm{~B} \mid \mathrm{A})$ - [i.e. the second constituent given prior occurrence of the first]. Since estimates for the conditional event will, by definition, be higher than those of the singular constituent $[p(\mathrm{~B} \mid \mathrm{A})>p(\mathrm{~B})]$ such as situation is more likely to give rise to CEs (cf. Fisk, 2002; Fisk \& Pidgeon, 1998).

${ }^{3}$ Here, the fictitious Linda is described as being 31 years old, single, outspoken, and very bright, who majored in philosophy and who, as a student, had been deeply concerned with issues of discrimination and social justice and who had participated in antinuclear demonstrations with participants asked to rank the likelihood of eight
} 
In their alternative $A \rightarrow B$ paradigm Tversky and Kahneman (1983) claimed conjunction errors can also be generated whenever occurrence of the second constituent is viewed as being conditionally dependent upon occurrence of the first. In other words, because the second component offers a plausible explanation for the occurrence of the first, the second component makes the conjunction appear more likely than the just first component alone. To illustrate, a sudden drop in public consumption of oil will seem less likely than a sudden drop in oil consumption given a sharp rise in oil prices because in the latter conditional event, the second element (the rise in price) offers a plausible explanation for the first (the fall in consumption). These "causal conjunction errors" are common even for unlikely/unlikely (U/U) constituent combinations and presumably reflect peoples' tendency to seek plausible, non-chance explanations for co-occurring events. Locksley and Stangor (1984) make a similar point arguing that the presence of certain cues (e.g. the temporal proximity or perceived rarity of constituent events) shift attention away from normative statistics laws on to the search for causal explanations. Furthermore, comparatively rare events such as suicide tend to require several co-occurring factors (e.g., job loss, severe debt, family break-up and a loss of social support) before any explanation seems reasonable. In other words, it is the logical plausibility of what might cause a seemingly rare event that determines subjective probability estimates and thus CE generation (Locksley \& Stangor, 1984). This argument seems especially relevant to the misattribution biases associated with belief in the paranormal (cf. Wiseman \& Watt, 2006).

In sum, different psychological processes appear to underlie Tversky and Kahneman's $\mathrm{M} \rightarrow \mathrm{A}$ (representativeness) verses $\mathrm{A} \rightarrow \mathrm{B}$ (causal) accounts of the conjunction fallacy, with

outcomes including that Linda is an active feminist (representative outcome), that Linda is a bank teller (unrepresentative outcome) and that Linda is a bank teller and an active feminist (conjunctive outcome; italics added here). In their original study Tversky and Kahneman (1982) found the majority of participants (85\%) rated the conjunctive term more likely than the second constituent event (aka. the unrepresentative outcome) despite this being statistically impossible. 
only the latter requiring a perceived conditional relationship between constituent events. Indeed, for Tversky and Kahneman (1983) it is the perceived strength - not mere presence of constituents' conditional relationship that shapes CE generation, with a stronger conditional relationship leading to a stronger conjunction fallacy

Others dispute Tversky and Kahneman's A $\rightarrow$ B hypothesis. Yates and Carlson (1986) found no differences in CE rates for common verses rare constituents and claimed it is (a weighted average of) constituent probability estimates - not constituent relatedness - that shape conjunctive biases. Similarly, Thürling and Jungermann (1990) found the causal relationship between two hypothetical diseases A and B (i.e. whether or not disease B was possible a side effect of disease A) had no impact on either CE generation or estimates of the conjunctive terms probability. Base-rate likelihoods however did, with both CEs conjunctive estimates more pronounced when the probability of contracting one disease was high (around $35 \%)$ and the other low $(<1 \%)$. This suggests constituent causality alone is not sufficient to induce conjunction errors; a direct contradiction of the $\mathrm{A} \rightarrow \mathrm{B}$ hypothesis.

These early studies have since been criticized for failing to provide the appropriate context by which to judge causal conjunctions (Fabre, Caverni \& Jungermann, 1995). In response, Fabre and colleagues employed a within subjects design with respondents estimating probabilities across all levels of constituent relatedness, namely strongly causal (e.g., disease B is a common side effect of disease A), weakly causal (e.g., disease B is a possible side effect of disease A) or acausal (e.g., disease B is not mentioned in relation to disease A) conditions. As expected, strength of constituent relatedness had significant impact, with conjunctive probability estimates higher for both (a) strongly over weakly causally related and (b) causally related over unrelated comparisons. In a second study, the same authors replicated these differences and confirmed probability estimates reflected likelihood judgments rather than idiosyncratic mental representations of each disease. Together, these 
findings suggest causally related constituents are sufficient for CE generation providing observers are able to compare constituent relationships within an appropriate causal context (Fabre et al., 1995).

With evidence for paranormal believers' heightened susceptibility to both conjunctive errors (e.g., Rogers et al., 2009; 2011; 2016) and causal misattributions (Wiseman \& Watt, 2006), it seems reasonable to suggest they will be especially prone to making causal conjunction errors, even more so when constituent events appear to be strongly causally related (cf. Fabre et al., 1995; Tversky \& Kahneman, 1983). This claim has yet to be tested.

\subsection{The Potential Surprisingness of Constituent Events}

Another account of the conjunction fallacy focuses on the "potential surprise value" (PSV) of constituent events. According to Shackle (1969) subjective probability estimates reflect the extent to which events are able to surprise observers. For example, a rank outsider winning the Wimbledon tennis final will be judged more surprising - that is, subjectively less likely (LL) - than the top seed winning it (Fisk, 2017).

Crucially for Shackle, the PSV of the conjunctive term never exceeds that of the more surprising (less likely) constituent. Hence, when constituents are conditionally unrelated (so occurrence of one does not influence the perceived likelihood of the other), the PSV of the conjunctive term will be determined solely by the more surprising (less likely) constituent; that is by whichever of $p(\mathrm{~A})$ or $p(\mathrm{~B})$ is assigned the lower value. However, when constituents are perceived to be positively conditionally related (so occurrence of one makes the other seem more likely), the conjunctive PSV is determined by whichever of two outcomes - either (a) the second constituent alone or (b) the second constituent given prior occurrence of the first - is judged most surprisingly (less likely). In other words, conjunctive estimations for positively conditionally related events are determined by judgments of either the singular event $[p(\mathrm{~B}])$ or the conditional event $[p(\mathrm{~B} \backslash \mathrm{A})]$, whichever has the lower value (see also Fisk 
2002; Fisk \& Pidgeon, 1998). By logical extension, CEs involving positively conditionally related constituents arise when estimates of the conjunctive term exceed those of whichever constituent estimate $[p(\mathrm{~B})$ or $p(\mathrm{~B} \backslash \mathrm{A})]$ has the higher value ${ }^{4}$. At present, the reasons why this might occur are not well understood (Fisk, 2017). This reasoning does not apply when two events are negatively conditionally related (i.e. where occurrence of one event renders the other seemingly less probable). Here conjunctive probability estimates are based on the conditional term $[p(\mathrm{~B} \backslash \mathrm{A})]$ which, given the negative relationship between constituents, will be deemed less likely (more surprising) than either or both these two events.

Shackle's PSV account has been empirically supported. In the first of two studies, Fisk and Pidgeon (1998) found conjunction probability estimates were higher and CE generation more prominent when constituent pairs were conditionally related verses conditionally unrelated. However contrary to expectations, the strength of constituents' relationship calculated as difference between $p(\mathrm{~B} \mid \mathrm{A})$ minus $p(\mathrm{~B})$ - was not linked to CE generation. Follow-up work replicated these findings and additionally, tested the extent to which estimates of the first singular constituent $[p(\mathrm{~A})]$ and conditional statement $[p(\mathrm{~B} \mid \mathrm{A})]$ predicted estimates of the conjunctive term. Overall, beta coefficients for the conditional term were smaller when constituent pairs had a positive as opposed to either a negative or no conditional relationship supporting the view that CEs are determined by the potential surprise value of individual constituents. With parallel trends emerging for likely/likely (L/L), likely/unlikely (L/U), unlikely/likely (U/L) and unlikely/unlikely (U/U) constituent combinations, this effect appeared to be robust (Fisk \& Pidgeon, 1998).

\footnotetext{
${ }^{4}$ The assumption here is that respondents judge constituent B more surprisingly (subjectively less likely) than constituent A. Of course it is also possible some participants will do the opposite deem constituent A more surprisingly (less likely) than constituent B. In such cases, the conjunctive PSV is determined by whichever of $p(\mathrm{~A})$ or $p(\mathrm{~B} \backslash \mathrm{A})$ is assigned the lower estimation value. For simplicity, future discussion will assume respondents base their estimations on $\mathrm{B}$ rather than $\mathrm{A}$. Note that a more extreme situation can arise when estimates of the conditional event $[p(\mathrm{~B} \backslash \mathrm{A})]$ exceed estimates of both singular events $[p(\mathrm{~A})$ as well as $p(\mathrm{~B})]$. In such instances, it is possible some respondents will base their conjunctive estimates more on $p(\mathrm{~A})$ and less on $p(\mathrm{~B})$ rendering these conjunctive estimations even more fallacious.
} 
Fisk and Pidgeon (1998) also argue that the absolute magnitude of estimates for the more surprising (less likely) event will, under most conditions, play little if any role in fallacy generation. All other things being equal, the mere presence of conditionally related constituents should be sufficient for CEs to arise. Contrary to this assertion, Crisp and Feeney (2009) found the strength of constituents' causal relationship did have a significant impact on $\mathrm{CE}$ rates, with most errors generated for strongly causal, then weakly causal and fewest for acausal, constituent pairings. Crisp and Feeney speculated this might reflect observers finding it harder to generate plausible counter-examples to conjunctive outcomes.

To recap, several studies support Tversky and Kahneman's (1983) claim that conjunction errors arise whenever constituent events are (perceived to be) conditionally related, with some researchers claiming strongly related constituents lead to a bigger fallacy. Evidence for this $\mathrm{A} \rightarrow \mathrm{B}$ paradigm is however mixed. An alternative view forwarded by Fisk emphasizes the potential surprise value (PSV) of each constituent, at least when these are positive and conditionally related. These differing accounts of the conjunction fallacy, together with Tversky and Kahneman's (1983) original M $\rightarrow$ A paradigm, are summarized in Table 1. *** Table 1 here $* * *$

Researchers have yet to examine paranormal believers' susceptibility to making causal over acausal conjunction errors directly. As previously discussed, Rogers et al. (2011) found believers' proclivity for generating CE's was not caused by them either (a) judging one or both constituents more likely or (b) perceiving the subjectively less likely component as having a stronger functional association with conjunctive term. However, this work has several limitations. First, Rogers and colleagues did not experimentally manipulate conditionally related verses conditionally unrelated constituent events, only testing Fisk's surprisingness account via post hoc analysis of individual scenarios. Second, the same authors compared believer verses non-believer differences following scale dichotomization, a 
technique which has received considerable criticism (MacCallum, Zhang, Preacher \& Rucker, 2002). Finally, their study examined conjunctive biases in relation to global paranormal beliefs only. Evidence for the extent to which stronger believers (in different types of alleged paranormal phenomena) are prone to generating causal verses acausal CEs is currently lacking.

Given Fisk's surprise theory perspective - hence emphasis on the more surprising (subjectively less likely) constituent shaping conjunctive probability estimates (Fisk, 2002; Fisk \& Pidgeon, 1998) - the present study also investigates the extent to which less likely $\times$ relatedness type interactions predict CE generation. According to Fisk, when constituents are (perceived to be) positively conditionally related there is a potential for some observers to shift their focus away from the less likely event onto the conditional event - that is, from $p(\mathrm{~B})$ to $p(\mathrm{~B} \mid \mathrm{A})$ - when judging conjunctive probabilities, thereby rendering $\mathrm{CE}$ generation more likely. Such a shift in focus would manifest as the LL constituent $\times$ relatedness term predicting more CEs. The current study tests this assertion.

\subsection{Paranormal Belief Types}

Finally, previous work suggests individuals who endorse extrasensory perception (ESP) and/or psychokinesis (PK) are more prone to probabilistic reasoning - including conjunctive biases than those who believe in life after death (LAD), at least in part because LAD beliefs are shaped primarily by socio-cultural, philosophical and/or motivational factors not statistical sophistication (Rogers, 2014; Thalboure, 1996). Recently Rogers, Qualter and Wood (2016; Study 1) found PK believers judged a depicted coincidence experience more reflective of paranormal knowing than either ESP or LAD believers. Whilst follow-up work failed to replicate these trends (Rogers, Qualter \& Wood, 2016; Study 2) subsequent research by Rogers, Fisk and Lowrie (2016) found conjunctive biases were more prevalent amongst ESP and to a slightly lesser extent PK believers than it was amongst LAD believers, with the 
first two believer types making more CEs when background evidence (scenario content) was "inductively confirmed" by the second constituent ${ }^{5}$. With these data in mind, assessing the extent to which constituents' conditional relatedness might impact on CE generation (and CPEs) across these three types of paranormal belief seems warranted.

\subsection{Study Aims and Hypotheses}

The present research examines the extent to which belief in three types of alleged paranormal phenomena - ESP, PK and LAD - predict conjunction error generation across two levels of conditional relationship (related verses unrelated) between constituent pairs. It also examines the role paranormal belief and constituent relatedness play within Fisk's potential surprise account of the fallacy which, as stated earlier, emphasizes the relationship between component and conjunctive probability estimates. For linguistic convenience the two levels of conditional relatedness - currently "positively conditionally related" and "conditionally unrelated" - are hereafter abbreviated to "related" and "unrelated" respectively. Several hypotheses are advanced.

First, stronger paranormal believers will generate more CEs than individuals with less pronounced paranormal belief (H01).

Second, more CEs will be made for related over unrelated constituent events (H02).

Third, if stronger paranormal believers are prone to making more causal CEs then a significant belief $\times$ relatedness interaction will result, with stronger believers making more CEs for related (over unrelated) constituents relative to weaker paranormal believers (H03).

Fourth and from Fisk's surprisingness perspective, a significant less likely $\times$ relatedness interaction will emerge such higher estimates of the subjectively less likely constituent - defined

\footnotetext{
${ }^{5}$ Inductive confirmation occurs when the credibility of a hypothesis is heightened by previously acquired background evidence (Tentori, Crupi \& Russo, 2013).
} 
by which of $p(\mathrm{~A})$ or $p(\mathrm{~B} \backslash \mathrm{A})$ has the lower value - will predict more CEs albeit for related constituents only (H04).

By extension, a significant three-way paranormal belief $\times$ less likely $\times$ relatedness interaction will also be found such that more CEs will be generated by stronger paranormal believers who provide higher estimates of the less likely constituent relative to weaker paranormal believers who do the same, albeit for related events only (H05).

Finally, the hypothesized belief-based trends described above will be more pronounced for ESP and PK, relative to LAD, beliefs (H06).

\section{Method}

\section{$\underline{2.1 \text { Participants }}$}

One hundred and sixty members of the UK general public were sampled with 130 completed questionnaires returned; a response rate of $81.3 \%$. Respondents were aged 16 to 72 years $(M=34.4$ years; $S D=13.3$ years) with most being female $(57.3 \%)$, of Caucasian ethnicity (91.4\%) and either employed (60.7\%) else in full time higher education (18.8\%). Two-fifths were qualified to undergraduate degree level or higher (41.5\%) with an eighth attaining the same level of qualification in math, statistics and/or psychology (12.4\%). No other demographic details were taken ${ }^{6}$.

\section{$\underline{2.2 \text { Design and Analyses }}$}

Hypotheses were tested via repeated measures Generalized Linear Mixed Model analyses, one per paranormal belief type. Linear Mixed Modeling (LMM) - also known as multilevel linear modeling (MLM) - is an extension of standard regression analysis which is more flexible in that it can incorporate factors that are hierarchically clustered or "nested" within others. LMM is also more flexible for several other reasons. For instance, it can differentiate

\footnotetext{
${ }^{6}$ Respondents reporting 'other' levels of qualification either generally $(n=10)$ and/or specifically in math/stats/psychology $(n=3)$ are excluded from these figures.
} 
between fixed verses random effects and can overcome problems associated with missing data, non-independent observations, non-homogeneous regression slopes, non-constant error variance and, for repeated measures designs, non-sphericity. Additionally, Generalized LMM analysis (GLMM) can be applied to non-normal (e.g., binary) outcomes where the relationship between predictors and the criterion measure is non-linear (Field, 2013; Norušis, 2007; Twisk, 2006). Given these advantages, GLMM was deemed more robust and more suitable for current purposes.

A total of three GLMMs were undertaken, in each case with eleven predictor variables simultaneously entered. These predictors were as follows: paranormal belief type (either ESP, PK or LAD beliefs), constituent relatedness type (related verses unrelated), the belief $\times$ relatedness interaction terms, estimates of the subjectively less likely (LL) and for completeness the subjectively more likely (ML) constituents plus six two and three-way belief-based interaction terms as described in the results section below. Interaction terms were added to test whether paranormal belief effects were consistent across the two levels of constituent relatedness. All predictors were treated as fixed factors with respondents' eight CE scores (one per scenario; the level 1 variable) treated as random factors as if clustered within each individual (the contextual variable). Each GLMM also included a random intercept term with any significant correlates found in preliminary analysis added to the model as potential covariates. Prior to analyses, all non-dichotomous predictors were subjected to grand mean centering so as to enhance the interpretability of findings (see Field, 2013). In all cases, the presence (vs. absence) of a conjunction error served as the outcome measure with this assumed to be linearly related to predictors through a logit link function.

Repeated measures covariance across scenarios was modeled via maximum likelihood (ML) estimation with models having either a scaled identity (specifying homogeneity of variance and zero covariances); a diagonal (specifying heterogeneity of variances), a first 
order auto-regressive (AR1; specifying homogeneity of variance and systematically correlated covariances), or a compound symmetry (specifying homogeneity of variance and uniform non-zero covariances) covariance structure. Finally, models were examined initially with the intercept term - which broadly speaking accounts for all variance not captured by the entered predictors (Field, 2013) - assumed to be random. These analyses were duplicated except this time with the intercept term assumed to be fixed. Comparison of the random verses fixed intercept models would isolate any effect the former might have on the proportion of classification successes.

\section{$\underline{2.3 \text { Materials }}$}

Questionnaire packs containing a brief, the scenario judgments, paranormal belief and demographics questionnaires (described below) plus a detachable debrief sheet were created. A second version of the pack - with reversed placement of the scenario judgments verses paranormal belief questionnaires - was created to counter potential order effects.

\subsubsection{Scenario Judgments Questionnaire (SJQ): The SJQ initially comprised sixteen} hypothetical scenarios depicting a range of non-paranormal events (e.g., receiving an inheritance, winning a marrow competition) taken, else adapted, from those developed by Rogers et al. (2011). This number was reduced to eight following pilot testing (see below). Based on each scenario's content or “background information (cf. Tentori et al., 2013), respondents were required to make three probability estimations; one for the first singular constituent $[p(\mathrm{~A})]$, one for the second $[p(\mathrm{~B})]$ and one for their co-occurrence; that is for the conjunctive term $[p(\mathrm{~A} \& \mathrm{~B})]$. All estimates were framed as "chances in 100 " with, for clarity, a worked example provided in SJQ instructions.

For current purposes, the first constituent was depicted as being either positively conditionally related else conditionally unrelated to the second. This experimental manipulation in constituent relatedness type (related verses unrelated) served as a two level 
independent variable. The second constituent within each scenario remained the same across both versions. As such, the notion of conditional relatedness is operationalised as the degree to which the second constituent is deemed reliant upon or a consequence of the first. To illustrate consider Scenario 01 entitled "inheritance". For the related version respondents had to estimate the chances in 100 that (a) Alan is told he was his uncle's favorite living relative; that (b) Alan is told he will inherit his uncle's entire $£ 1$ million estate; and finally that (c) Alan is told his uncle died of heart failure and Alan is told he will inherit his uncle's entire $£ 1$ million estate (italics added here). In the corresponding unrelated version, statement (a) is replaced by "Alan is told his uncle died at two o'clock in the afternoon" with statement (b) unchanged. Hence, in Scenario 01 conditional relatedness reflects the degree to which Alan inheriting his uncle's entire estate is perceived as being reliant upon or a consequence of him being his uncle's favorite (related version) as opposed to the fact that his uncle had died early one afternoon (unrelated version). Copies of the 16 scenarios plus associated constituent statements are available from the first author.

Generally, lower probability estimates indicate respondents judge a given event subjectively less likely hence more surprising. Conjunction errors were made whenever the conjunctive term was rated more likely than either or both of the two singular constituent events (cf. Tversky \& Kahneman, 1983).

\subsubsection{Belief in the Paranormal: This was assessed via the Australian Sheep-Goat Scale} (ASGS; Thalbourne \& Delin, 1993), a popular, psychometrically sound, 18-item measure of belief in three core paranormal concepts - namely extrasensory perception (ESP), psychokinesis (PK) and life after death (LAD) - across three subscales containing ten, five and three items respectively (Thalbourne, 2010). All ASGS items were rated along a 7-point Likert scale ranging from 1 'strongly disagree' to 7 'strongly agree' (cf. Rogers et al., 2011) with higher scores indicating stronger belief in each alleged paranormal phenomena. Given 
criticisms of median split analysis (MacCallum et al., 2002) continuous belief measures were retained.

2.3.3 Demographics: Respondents' gender, age, ethnicity (16 categories), occupational status (12 categories) and levels of both general and mathematics/statistics/psychology-specific qualifications (from 1 'no qualifications' to 5 'postgraduate/professional qualifications') were assessed.

\subsection{Procedure}

Respondents for the main study were recruited opportunistically via medium sized businesses (e.g. corporate coffee shops, leisure centers) in various locations within NorthWest England (e.g., Preston, Blackpool, Chorley). Having obtained appropriate permission from company management, members of the public were approached and asked if they would take part in a study of "beliefs about the likelihood of certain events happening". Volunteers were handed a randomly allocated questionnaire pack containing full instructions (including assurances of anonymity and confidentiality), the aforementioned SJQ, ASGS and demographic questionnaires with a detachable debrief (containing study and welfare agency details) also supplied. No payment or time limits were given. Completed questionnaires were returned to the researcher (PR or EL) in person else via the post. All aspects of the study conformed to the University's School of Psychology as well as British Psychological Society (BPS) ethical guidelines.

\section{Results}

\subsection{Manipulation Check}

Pilot testing was undertaken to assess the efficacy of experimental manipulations in constituent relatedness type, with volunteers $(n=54 ; 55.4 \%$ female; aged $19-71$ years; $M=30.1 ; S D=11.9 ;$ response rate $90.0 \%$ ) recruited opportunistically from public areas (e.g. the library, refectory) of a large university in North-West England. As previously noted, 
sixteen scenarios were taken from those originally developed by Rogers et al. (2011) with, for piloting purposes, each followed by two statements namely (a) one version of the first singular constituent (related or unrelated) plus (b) the second singular constituent (unchanging). For pilot testing, respondents were then asked "How likely is the second event?" plus "How likely is the second event given that the first event is true?" with ratings potentially ranging from 0 to 100 . These two likelihood estimates - denoted $p(\mathrm{~B})$ and $p(\mathrm{~B} \backslash \mathrm{A})$ respectively - served as dependent measures. Detailed instructions including a worked example were provided. Following procedure adopted by Fisk and Pidgeon (1998), paired samples $t$-tests assessed the relationship between these two probability estimates. For experimental manipulations to be effective, $p(\mathrm{~B} \mid \mathrm{A})$ minus $p(\mathrm{~B})$ differences needed to be larger for conditionally related constituent pairings but not for unrelated event pairings.

Results of this pilot work are summarized in Table 2. As this shows $t$-tests for nine related event pairs reached significance ( $p$ 's $\leq .034$; one-tailed), with associated effects sizes (Cohen's d) ranging from -.59 to -1.39 . In each of these nine cases, $p(\mathrm{~B} \mid \mathrm{A})$ values were higher than $p(\mathrm{~B})$ values the implication being that experimental manipulations in constituent relatedness had, for these nine scenarios, been successful. Pilot H01 is supported

$$
\text { *** Table } 2 \text { here } * * *
$$

Comparable $p(\mathrm{~B} \mid \mathrm{A})$ minus $p(\mathrm{~B})$ differences did not emerge for unrelated event pairings in 15 of the 16 scenarios examined (93.8\%). The single noticeable exception was for Scenario 09 ("horse") where $p(\mathrm{~B} \mid \mathrm{A})$ values were significantly higher than $p(\mathrm{~B})$ values. This difference renders Scenario 09 unsuitable for current purposes so it was dropped. In sum, eight of the original sixteen scenarios - numbers $01,02,04,07,11,14,15$ and 16 - were deemed suitable for use in the main study. Related and unrelated versions of each were randomly allocated.

\subsection{Main Study: Preliminary Data Screening and Descriptives}


In the main study seven respondents failed to provide the full complement of 24 probability estimates (i.e. three for each of the eight scenarios). Because missing data is not a problem for GLMM so these individuals were retained. However, three underage (pre-16 year old) respondents were dropped from the data set (final $n=127 ; 1016$ cases).

3.2.1 Belief in the Paranormal: As Table 3 shows, all three paranormal belief subscales presented good internal reliability ( $\alpha$ 's $\geq .79$ ) with two - PK and LAD beliefs - presenting non-normality. Based on a significance cut off of $p=.01$ (Clark-Carter, 2004) PK beliefs were slightly skewed. No outliers were found for any ASGS measure and with no systematic biases evident all data were retained. Overall, levels of ESP, PK and LAD belief were comparable to those reported elsewhere (e.g., Rogers et al., 2016).

*** Table 3 here $* * *$

\subsubsection{Conjunction Errors: Table 4 presents mean constituent and conjunction probability} estimates together with the percentage of responses resulting in a conjunction error (CE) for each of the eight retained scenarios. As Table 4 shows, some proportion of respondents made CEs for each scenario (range $28.3 \%$ to $53.3 \%$; median=37.9; $M=38.4 ; S D=8.4$ ) rendering all suitable for inclusion in Study 2.

Overall, a moderate number of CEs was generated with the distribution of total CEs having a slight but non-significant positive skew (see Table 5). In general, more CEs were made for related over unrelated constituent pairs, $\chi^{2}(1)=8.14 ; p=.004$; two-tailed. A single CE outlier was found and subsequently removed.

$$
\text { *** Tables } 4 \text { and } 5 \text { here } * * *
$$

\section{$\underline{3.3 \text { Correlations }}$}

As Table 6 displays, PK beliefs correlated with the number of CEs made in total as well as for unrelated constituent pairings. Unsurprisingly, the three paranormal belief types were highly inter-correlated. In terms of respondent demographics, ESP beliefs correlated 
negatively with Caucasian (vs. non-Caucasian) ethnicity whilst LAD beliefs correlate negatively with both general and math/stats/psychology-specific qualifications. Noticeably, CE rates for conditionally related, unrelated and all constituent pairings were negatively associated with general qualifications - but not math/statistics/psychology-specific qualification levels. Future analyses will control for this single demographic measure. No evidence of predictor multicollinearity was found (absolute $r$ 's $<.27$ ).

$* * *$ Table 6 here $* * *$

\subsection{Predictors of Conjunction Error Generation}

Three GLMM analyses examined the extent to which paranormal belief type (either ESP, PK or LAD beliefs), constituent relatedness, general qualification levels, probability estimates for both the subjectively less likely (LL) and subjectively more likely (ML) constituent events plus relevant interaction terms predicted the presence (vs. absence) of conjunction errors for each of the eight retained scenarios. As also stated, all nondichotomous predictors were subjected to grand mean centering before a series of GLMMs each assessing a different covariance structure - was performed. The final sample of 1016 cases was deemed adequate for current purposes (cf. Fisk, 2017).

In all analyses, compound symmetry (CS) structures failed to converge with first-order auto-regressive (AR1) structures generating the best fit for both fixed and random intercept models. For the most part, adding each additional predictor improved model fit to a significant degree, with inclusion of a random (verses fixed) intercept term doing the same. Summaries of these goodness-of-fit data are available on request from the first author.

As Table 7 shows, the three models with a fixed intercept correctly classified approximately $18-23 \%$ of conjunction errors, around $89-90 \%$ of non-errors and roughly $62-$ $63 \%$ of all responses regardless of which paranormal belief type served as a predictor. Inclusion of the random intercept term improved classification accuracy for errors to around 
40-42\%, had minimal impact on accuracy for non-errors with all three remaining approximately $89 \%$, and improved classification accuracy for all responses slightly to just over $70 \%$ in all models. Given the conceptual necessity of including a random intercept term in GLMM for repeated measures (Twisk, 2006), only random intercept models with an AR1 covariance structure are discussed further.

$* * *$ Table 7 here $* * *$

Table 8 presents inferential statistics for each of the three belief-based models. In each case the ARI diagonal statistic - which represents the estimated residual variance in outcome scores across different level 1 variables (here, the eight scenarios) - was highly significant implying the likelihood of a CE being made (vs. not made) varied for each scenario. Similarly, the three ARl rho statistics (aka. intraclass correlation coefficients) - which reflects the proportion of total variance in outcomes that is attributable to the same "contextual" variable (here, each respondent) - were all non-significant. This implication here is that unexamined factors within each class (respondent) had no impact on CE generation (Field, 2013; Norušis, 2007).

*** Table 8 here $* * *$

As Table 8 clearly shows, general qualifications were a highly significant negative predictor of CE generation in all three models. With all other predictors set at the respective means ("averaged") a unit increase in general qualification level decreased the odds of making (verses not making) a CE by approximately a quarter [ $\exp (b)$ 's from .74 to .77]. All demographic measures entered into current GLMM analyses served as potential covariates meaning associated hypotheses were not advanced. Subsequent findings should be treated as if general qualifications are controlled for.

Table 8 also shows that of the three paranormal belief types, PK beliefs alone predicted the making (over non-making) of CEs to a statistically significant degree. More precisely, 
with all other predictors set at the respective means ("averaged") a unit increase in PK beliefs increased the odds of making (verses not making) a CE by approximately a quarter $[\exp (b)=1.26]$. With parallel trends not emerging for belief in either ESP or LAD beliefs, H01 is partially supported.

Constituent relatedness type was also a positive predictor of CEs in all three models. Thus, presentation of related (vs. unrelated) constituent events increased the odds of CE generation by just over half [exp(b)'s from 1.56 to 1.63$]$. As such, H02 is fully supported.

Contrary to expectations, no significant belief x relatedness type interactions emerged meaning that with all other measures averaged, stronger paranormal believers made as many CEs for related (vs. unrelated) constituents as did those with weaker paranormal beliefs. With this the case for all three belief types, H03 is completely unsupported.

Estimates for the subjectively less likely (LL) constituent also predicted CE generation, again in all three belief-based models. However, while Fisk (2002; Fisk \& Pidgeon, 1998) has demonstrated that the conjunctive probability is largely determined by the magnitude of the LL event (implying a positive relationship), currently findings suggest, paradoxically, that LL and conjunctive probability estimates are negatively related. Specifically, with all other predictor variables averaged, a unit increase in less likely estimations decreased the odds of a CE generation by around $1-2 \%[\exp (b)$ 's from .98 to .99]. Because trends run counter to those anticipated, H04 is completely unsupported. As expected, estimates of the subjectively more likely (ML) constituent also failed to predict CEs.

The lack of any significant three-way interactions involving subjectively less likely estimates means H05 is unsupported too. It seems, stronger paranormal believers who provided higher less likely estimations made just as many CEs for related verses unrelated constituent events as weaker believers who gave higher less likely estimations as well as 
stronger believers who gave lower less likely estimations. In sum, H05 too is completely unsupported.

Finally, inspection of odds ratios across the three belief-based models confirmed PK beliefs [ $\exp (b)=1.26]$ were more predictive of CE generation than ESP beliefs [ $\exp (b)=1.13]$ which in turn, appeared slightly more predictive of CEs than LAD beliefs [ $\exp (b)=1.08]$. These odds ratios suggest PK beliefs are more strongly associated with $\mathrm{CE}$ generation than both ESP and LAD belief. Subsequent post hoc GLMM analysis with the three belief measures entered as predictors (and general qualification level again controlled for) was performed to verify these apparent differences. Results confirmed only PK beliefs predicted more CEs to a significant degree, $b=.22 ; t=2.38 ; p=.018 ; \exp (b)=1.25,[1.04,1.51]$. In contrast, ESP beliefs, $b=-.07 ; t=-.53 ; p=.596 ; \exp (b)=.93[.73,1.20]$ and LAD beliefs, $b=.01$; $t=-.09 ; p=.930 ; \exp (b)=1.01,[.83,1.23]$ were both far from significant as predictors of CE generation. In sum, H06 is also supported.

\section{Discussion}

\subsection{Predicting Conjunction Error Generation}

The present research produced a number of noteworthy findings. Subsequent discussion is for GLMM data with respondents' general level of qualification controlled for. Consideration this demographic covariate is reserved for the "Additional Findings" section below.

First, only one of the three paranormal belief types - PK beliefs - predicted CE generation to a significant degree, with stronger PK believers making more errors than individuals with less pronounced PK beliefs. This finding supports previous claims that a belief in (certain types of) paranormal phenomena is associated with a more pronounced conjunction fallacy (Brotherton \& French, 2014; Rogers et al., 2009; 2011; 2016). However, present trends suggest it is only individuals who more strongly endorse the veracity of psychokinesis (mindover-matter) who are especially prone to the fallacy with, parallel conjunctive biases not 
shared by those more strongly endorsing either ESP or LAD. Rogers, Fisk and Lowrie (2016) found stronger PK as well as stronger ESP believers were more error prone in this conjunctive context (see also Rogers Qualter \& Wood, 2016)

Second, as hypothesized, constituent relatedness predicted more CE generation with (all) respondents making more errors for (positively conditionally) related than they did for (conditionally) unrelated constituents. This finding supports previous claims that conjunction biases emerge whenever occurrence of the second constituent is perceived as being reliant on or causally related to occurrence of the first (Crisp \& Feeney, 2009; Fabre et al., 1995; Fisk \& Pidgeon, 1998; Locksley \& Stangor, 1984) at least when an appropriate (within subjects) causal context is in place (Fabre et al., 1995).

Third, but contrary to expectations, those with stronger paranormal beliefs made as many CEs for related (over unrelated) constituents as did individuals with less pronounced paranormal beliefs. This was the case regardless of whether respondents endorsed ESP, PK or LAD. The implication here is that stronger paranormal believers (all kinds) are just as sensitive to constituents' conditional relatedness, and so just as (but no more) prone to making causal conjunction errors, as their skeptical counterparts. Furthermore, it seems PK believers' heightened propensity for conjunctive biases is not shaped by their perception of the second constituent's reliance or causal dependence upon the first (e.g., Crisp \& Feeney, 2009). Similar claims in relation to global paranormal believers have been made elsewhere (Rogers et al., 2011).

Fourth, estimates for the subjectively less likely (LL) constituent event significantly predicted conjunctive biases. Contrary to hypotheses, higher LL ratings were linked to the making of fewer, not more, CEs. This result was evident in all three belief -based models. However, it should be noted that despite being significant, odds ratios were very close to unity with higher estimations of the subjectively less likely event leading to no more than a 
$2 \%$ reduction in CE generation. Such a small effect casts doubt over the robustness of current findings with again, replication needed.

Lastly and again contrary to hypotheses, the three-way paranormal belief $\times$ relatedness $\times$ less likely interactions failed to reach significance in all three belief-based models. The implication here is that event surprisingness had the same impact on CE generation regardless of both (a) the strength and/or type of respondents' paranormal endorsement and/or (b) the nature of constituents' conditional relationship (related verses unrelated). By extension, it appears those with stronger PK beliefs did not make more CEs because they viewed either (a) the second constituent alone (i.e. the singular event) or (b) the second constituent given prior occurrence of the first (i.e. the conditional event) as being less likely - or by definition, any more surprising- than individuals with weaker PK beliefs. Earlier claims to this effect are now extended beyond global paranormal beliefs (Rogers et al., 2011) to a more narrowly defined paranormal endorsement.

\subsection{Theoretical Implications}

Current findings suggest individuals with a stronger endorsement of one specific type of alleged paranormal phenomena, namely psychokinesis, are more susceptible to making conjunction errors - and thus to overestimating the likelihood of co-occurring relative to constituent events (Tversky \& Kahneman, 1982; 1983) - than are those with less pronounced PK beliefs. Current findings are therefore consistent with most (Brotherton \& French, 2014; Dagnall, Drinkwater et al., 2016; Prike et al., 2017; Rogers et al., 2009; 2011; 2016) but not all (Dagnall, Denovan et al., 2016; Dagnall et al., 2007; Dagnall et al., 2014) previous work on this topic.

As already implied, the range and complexity of factors associated with adult paranormality (French \& Stone, 20141 Irwin, 2009) means even strict normative reasoning will not prevent at least some paranormal belief formation occurring. Given this caveat, 
present findings are consistent with the broader view that belief in (some types of) ostensibly paranormal phenomena - here, a specific endorsement of PK - is associated with more errors in probabilistic reasoning (Rogers, 2014; Rogers et al., 2016; Study 1; Wiseman \& Watt, 2006) and thus certain types of cognitive "deficit" (Irwin, 2009). This remains the case despite current evidence suggesting PK beliefs are unrelated to both general and math/statistics psychology-specific qualification levels. Whilst the former adds to generally mixed evidence for paranormal believers being less well-educated, the latter fails to support previous claims that paranormal endorsement is less prominent amongst those trained in a scientific discipline (see French \& Stone, 2014; Irwin, 2009).

With current scenarios all depicting a non-paranormal event, contextual cues implicating the possibility of PK (cf. Locksley \& Stangor, 1984) were not immediately obvious. Nevertheless, it is possible stronger PK believers overlooked normative statistical rules and misattributed what was for them a plausible, presumably paranormal and perhaps even PKbased mechanism to explain co-occurring events (Rogers, Qualter \& Wood, 2016; Study 1; Wiseman \& Watt, 2006). In the "pregnancy" case for instance, the sister's surprise visit may have been seen as the result of one twin's direct mental influence over the other. Likewise, winning the "marrow" competition might have been deemed reasonable evidence for direct mental influence on livings systems (DMILS). Finally, in the sixteenth century "house" scenario, a sudden infestation of rats might have been viewed as one consequence of recurrent spontaneous psychokinesis or, as RSPK is more commonly known, poltergeist activity $^{7}$. At this stage, such interpretations are merely conjecture. Also, it is difficult to see how parallel PK-based interpretations could be applied to the remaining six cases (i.e. inheritance, career, woman, sleep and murder) given their scenario content.

\footnotetext{
${ }^{7}$ For discussion of both DMILS and RSPK see Irwin and Watt (2007).
} 
A second possibility is that PK believers hold an arguably more extreme paranormal worldview (cf. Irwin \& Watt, 2007) that for some, as yet undetermined, reason renders them more susceptible to conjunctive biases. Whilst rare events normally require several cooccurring factors before a plausible explanation can be constructed (Locksley \& Stangor, 1984) for believers, particularly those holding a more extreme paranormal worldview, a single metaphysical concept such as psychokinesis will often suffice (Wiseman \& Watt, 2006). At least one other study has found coincidence misperceptions may be unique to PK over types of paranormal believer (Rogers, Qualter \& Wood, 2016; Study 1). As these authors suggest, it is possible PK believers have a more extreme and noticeably "looser" mental representation of what constitutes a remarkable coincidence and thus a lower threshold for being surprised by co-occurrences relative to other types of paranormal believer not to mention paranormal skeptics (cf. Hadlaczky \& Westerlund, 2011). If true, PK believers would require less subjective evidence of relatedness before they start to see meaningful patterns in essentially random stimuli (e.g., Brugger \& Taylor, 2003), a process recently termed "patternicity" (Shermer, 2011; p.60). However, current evidence that PK believers remain unaffected by differing levels of constituent relatedness (related verses unrelated) weakens this argument. It should also be noted that follow-up work by Rogers et al. (2016; Study 2) failed to replicate their initial (Study 1) finding, leaving the uniqueness of PK believers' lower threshold for being surprised by co-occurrences open to question.

A related possibility is that PK believers failed to judge the second constituent less likely (more surprising) when this followed the first because such an outcome actually conformed to their paranormal worldview. If true, PK believers would not only remain unsurprised by occurrence of the second constituent they might, under the circumstances, have even come to expect it. Thus, what for most people would be an unlikely/unlikely (U/U) combination would, for PK believers, be an unlikely/likely (U/L) combination of constituent events. The 
implication here is that PK believers misperceive positively conditionally related constituents as being negatively conditionally related, with the usual limits on CE generation for U/L combinations (cf. Fisk \& Pidgeon, 1998) for some reason not applying. To illustrate, consider the same person winning both the UK National Lottery ("Lotto") and the Euromillions lottery jackpots on the same day. With objective odds of 45 million-to-1 and 140 million-to-1 respectively (Lottoland, 2016), co-occurrence of these two independent and highly unlikely lottery wins would, for most people, seem too remarkable-a-coincidence even to contemplate. But for those who believe in the veracity of money spells - hence of consciously directed PK (Greenwood \& Airey, 2009) - such co-occurrences may be far from remarkable. Such a worldview might explain why more extreme PK believers present a stronger fallacy in general. Whilst the current lack of a PK belief $\times$ less likely interaction suggests this is not the case, previous evidence that stronger (ESP and) PK believers are prone to more CEs for confirmatory (over disconfirmatory) conjunctions than their skeptical counterparts (Rogers, Fisk \& Lowrie, 2016) implies it is at least a possibility. Further work exploring the relationship between paranormal beliefs and negatively conditionally related constituent events seems worthwhile.

A final option is that current trends for PK believers are a spurious artifact of multiple testing. As already noted, initial evidence that PK believers judged a seemingly remarkable coincidence (co-occurrence) more reflective of paranormal knowing (Rogers, Qualter \& Wood, 2016; Study 1) was not replicated (Rogers, Qualter \& Wood, 2016; Study 2) and it is possible similar non-replication might apply to current trends. With this in mind, further research is needed to verify the findings reported here.

\section{$\underline{4.3 \text { Additional Findings }}$}

Correlations revealed a number of other noteworthy trends. First, and as one might expect, generally more qualified individuals made fewer CEs than those with less general education 
attainment. In contrast, respondents' level of qualification specifically in math, statistics and/or psychology was unrelated to CE rates. This was true regardless of whether constituents were depicted as being conditionally unrelated or positively conditionally related. These trends are consistent with previous evidence that level of statistical training and/or sophistication has little impact on fallacy generation (e.g., Msaouel, Kappos, Tasoulis, Apostolopoulos, Lekkas et al., 2014; Rogers et al., 2011; Tversky \& Kahneman, 1982; although see e.g., Benassi \& Knoth, 1993; Rogers et al., 2009) ${ }^{8}$.

It is noticeable that many more respondents were educated to undergraduate level generally (38.9\%) than specifically in math, statistics and/or psychology (11.3\%); a ratio of almost 3-to-1. Frequencies for those attaining higher degrees is even more contrasting; a sixth of the sample attaining a postgraduate/professional qualification regardless of discipline (17.6\%) compared only a very small minority - less than a twentieth - doing likewise in math, statistics and/or psychology (1.7\%); a ratio in excess of 10-to-1. Whilst unsurprising, the preponderance of those with more years of formal, post-compulsory educational attainment regardless of discipline may explain why only general qualification levels were associated with lower CE generation. One possibility is that more qualified individuals had better linguistic understanding of task instructions and/or the semantics, namely the fact that one singular constituent does not automatically negate the other; in short, that $p(\mathrm{~A})$ was not equivalent to $p$ (A \& not B). In line with Fisk (2017) such interpretation seems unlikely. A second possibility is that generally better qualified individuals acquired some form of reasoning or critical thinking ability - perhaps improved verbatim matching/monitoring or better task mindfulness (cf. Liberali, Reyna, Furlan, Stein \& Pardo, 2012) - that is more suited to judging conjunctive outcomes than statistical training alone. A third is that, by virtue

\footnotetext{
${ }^{8}$ Despite psychology degrees dedicating far less time to statistical techniques and numerical problem solving than degrees in math and statistics, there appears to be little difference in the impact these three disciplines have on fallacy generation (Prike et al., 2017).
} 
of their broader education and university experiences, those with higher general qualifications were, for some as yet unknown reason, less surprised by the subjectively less likely (LL) constituent event which, as noted earlier, is key to shaping conjunctive probabilities estimates and potential CE generation (Fisk, 2002; Fisk \& Pidgeon, 1996). Subsequent testing in which all $\mathrm{LL} \times$ qualification correlations were significant and of similar magnitude except for $\mathrm{LL} \times$ math/statistics/psychology-specific qualifications given related constituents (causal conjunctions) offers some support for this suggestion ${ }^{9}$. A final possibility is that current differences in the degree to which general verses math/statistics/psychology-specific qualification levels co-varied with fallacy generation (and/or LL estimations) was merely an artifact of the current experimental design. In this case, unambiguously attributing differences in $\mathrm{CE}$ rates to general educational attainment would not be possible. More work is needed to determine which, if any, of these possibilities holds true.

Second, individuals with stronger ESP beliefs tended to be of non-Caucasian rather than Caucasian ethnicity whilst those with stronger LAD beliefs tended to be less well educated both generally and specifically in terms of math, statistics and/or psychology. These findings are consistent with much, if not all, previous work on demographic correlates of adult paranormality with the latter supporting Otis and Alcock's (1982) claim that afterlife endorsement is associated with lower educational attainment (for reviews see French \& Stone, 2014; Irwin, 2009).

\subsection{Methodological issues and Ideas for Future Research}

The current study has several strengths including the use of community-based sampling with acceptable $n$, multiple vignettes, pilot testing to validate levels of constituent relatedness

\footnotetext{
${ }^{9}$ For scenarios incorporating unrelated constituent events, LL ratings correlated with both general and math/statistics/ psychology-specific qualifications ( $r=-.13 ; p=.008$; and $r=-.14 ; p=.002$ respectively). When scenarios contained positively conditionally related constituents, LL estimates correlated negatively with general but not with math/statistics/ psychology-specific qualifications ( $r=-.12 ; p=.013$; and $r=-.04 ; p=.437 ; n s$ respectively).
} 
and employment of a well-established, psychometrically sound measure of paranormal belief. Additionally, (Generalized) Linear Mixed Modeling allowed assumptions about missing data, the homogeneity of regression slops and the independence of residuals to be relaxed. Finally, by incorporating a repeated measures component respondents were given the appropriate "causal context" for predictors of CE generation to be examined (cf. Fabre et al., 1985). Despite this methodological rigor a number of limitations are worthy of mention.

First, comparison of conditionally related verses conditionally unrelated statement pairs at the pilot stage was assessed using unadjusted alpha values of .05. Possible occurrence of Type 1 errors may have meant some of the statement pairs classified as being "conditionally related" may not have been so. Conversely, potential occurrence of Type 2 errors may have meant some statement pairs labeled "conditionally unrelated" may, in fact, have been related. However, this would also have increased the likelihood of Type 2 errors emerging in the main study, rendering it more difficult to identify significant relatedness type effects on $\mathrm{CE}$ generation. Since significant relatedness type effects were found in the main study, Type 2 errors can be excluded (although the effect of relatedness may still be stronger than our results suggest). Moreover, with full Bonferroni correction shown to increase the likelihood of Type 2 errors at the level of individual comparisons (e.g., Narum, 2006) such adjustment was deemed unsuitable for current IV manipulation checks.

Second, scenarios were clearly non-paranormal in content meaning opportunities to misattribute paranormal relatedness, and thus make paranormally-driven causal CEs, may have been limited. Whilst previous evidence suggests believers are unaffected by the depicted paranormality of scenarios (Rogers et al., 2007; Rogers et al., 2011) further research should consider contrasting paranormal verses non-paranormal event types and/or employing a wider variety of conjunctive scenarios. 
Third, despite scenarios depicting an unlikely/unlikely constituent combination it is possible some respondents perceived the second event to be even less likely (even more surprising) once the first unlikely event had already occurred. In other words, respondents may have misperceived unlikely/unlikely (U/U) combinations as having a negative conditional relationship even for scenarios where no conditional relationship existed. Under these circumstances, estimates of the conjunctive term can sometimes anchor on to the associated conditional term $[p(\mathrm{~B} \backslash \mathrm{A})]$ which may, in turn, be rated subjectively less likely (more surprising) than both singular events $[p(\mathrm{~A})$ and $p(\mathrm{~B})]$. With this in mind, and assuming probability estimates are randomly distributed around this anchor, most of the sample will fail to generate a conjunction error (Fisk \& Pidgeon, 1996). This might be especially relevant to individuals holding stronger paranormal (especially PK) beliefs. Future studies should test this possibility.

Fourth, the extent to which believers' susceptibility to conjunctive biases is shaped by the strength - rather than mere existence - of constituent relatedness remains unexplored. Given Crisp and Feeney's (2009) finding that more CEs are generated for strongly causal over weakly causal and, in turn, for weakly causal over acausal constituent pairs, research exploring stronger (PK) believers' CE generation across varying levels of conditional relatedness seems worthwhile.

Given recent claims by Dagnall, Denovan et al., (2016), future studies should also assess believers' proneness to conjunctive biases once more general randomness misperceptions are controlled for. Similarly, with conjunctive errors indicative of heuristical processing (Tversky \& Kahneman, 1983) and paranormal believers having a stronger preference for experiential over rational thinking styles (e.g. Aarnio, \& Lindeman, 2005; Irwin \& Wilson, 2013), future work should also examine the extent to which (PK) believers' proneness to CEs are influenced by their thinking style predilections. 
More broadly, the relatively low proportion of non-Caucasian respondents sampled $(8.6 \%)$ means the current study has less-than-perfect generalisability. This could be important given the influence ethnicity seems to have on at least some paranormal belief types (for reviews and critiques see French \& Stone, 2014; Irwin, 2009).

Finally, judgments may have been influenced by the order of scenarios within the SJQ (cf. Prike et al., 2017; Study 2). Additional counterbalancing should therefore be considered.

\section{$\underline{4.5 \text { Conclusion }}$}

The present study builds upon previous work to advance understanding of the relationship between stronger paranormal beliefs and CE generation. In particular, it sought to establish whether believers were more biased in their judgments of positively conditionally related over conditionally unrelated constituent events. No support for this hypothesis was found. Whilst stronger PK believers seem especially susceptible to making conjunction errors generally, this appears to be for reasons others than their greater sensitivity to the perceived conditional relatedness (causal dependence) of co-occurring events. More work is needed to replicate current evidence and, if confirmed, to establish the precise psychological processes underlying paranormal (PK) believers' proneness to the conjunction fallacy. 


\section{References}

Aarnio, K., \& Lindeman, M. (2005). Paranormal beliefs, education, and thinking styles. Personality \& Individual Differences, 39(7), 1227-1236.

doi:10.1016/j.paid.2005.04.009

Benassi, V. A., \& Knoth, R. L. (1993). The intractable conjunction fallacy: Statistical sophistication, instructional set, and training. Journal of Social Behavior \& Personality, 8(6), 83-96.

Bressan, P. (2002). The connection between random sequences, everyday coincidences and belief in the paranormal. Applied Cognitive Psychology, 16(1),17-34. doi: 10.1002/acp.754

Brotherton, R., \& French, C. C. (2014). Belief in conspiracy theories and susceptibility to the conjunction fallacy. Applied Cognitive Psychology, 28(2), 238-248. doi:10.1002/acp.2995

Brugger, P., Regard, M., Landis, T., Cook, N., Krebs, D., \& Niederberger, J. (1993).

'Meaningful' patterns in visual noise: Effects of lateral stimulation and the observer's belief in ESP. Psychopathology, 26(5-6), 261-265. doi:10.1159/000284831.

Brugger, P., \& Taylor, K. I. (2003). ESP: Extrasensory perception or effect of subjective probability? Journal of Consciousness Studies, 10(6-7), 221-246

Cardeña, E., Lynn, S. J., \& Krippner, S. (2014). Varieties of anomalous experience: Examining the scientific evidence (2nd edition). Washington, DC, US: American Psychological Association. doi:10.1037/14258-000

Clark-Carter, D. (2004). Quantitative psychological research: A student's handbook. Hove, UK: Psychology Press

Crisp, A., \& Feeney, A. (2009). Causal conjunction fallacies: The roles of causal strength and mental resources. Quarterly Journal of Experimental Psychology, 62(12), 2320-2337. doi:10.1080/17470210902783638 
Dagnall, N., Denovan, A., Drinkwater, K., Parker, A., \& Clough, P. (2016). Toward a better understanding of the relationship between belief in the paranormal and statistical bias: The potential role of schizotypy. Frontiers in Psychology, 7, 1-14. doi: 10.3389/fpsyg.2016.01045

Dagnall, N., Drinkwater, K., Denovan, A., Parker, A., \& Rowley, K. (2016). Misperception of chance, conjunction, framing effects and belief in the paranormal: A further evaluation. Applied Cognitive Psychology, 30(3), 409-419. doi:10.1002/acp.3217

Dagnall, N., Drinkwater, K., Parker, A., \& Rowley, K. (2014). Misperception of chance, conjunction, belief in the paranormal and reality testing: A reappraisal. Applied Cognitive Psychology, 28(5), 711-719. doi:10.1002/acp.3057

Dagnall, N., Parker, A. \& Munley, G. (2007). Paranormal belief and reasoning. Personality \& Individual Differences, 43(6), 1406-1415. doi: 10.1016/j.paid.2007.04.017

Diaconis, P. \& Mosteller, F. (1989). Methods for studying coincidences. Journal of the American Statistical Association, 84(408), 853-861

Fabre, J., Caverni, J., \& Jungermann, H. (1995). Causality does influence conjunctive probability judgments if context and design allow for it. Organizational Behavior \& Human Decision Processes, 63(1), 1-5. doi:10.1006/obhd.1995.1056

Field, A. (2013). Discovering statistics using IBM SPSS statistics (4th edition). London: Sage

Fisk, J. E. (2002). Judgments under uncertainty: Representativeness or potential surprise? British Journal of Psychology, 93(4), 431-449. doi: 10.1348/000712602761381330

Fisk, J. E. (2017). Conjunction fallacy. In R. F. Pohl (ed.). Cognitive illusions: Intriguing phenomena in judgment, thinking and memory (2nd edition). (pp. 25-43). London: Routledge 
Fisk, J. E., \& Pidgeon, N. (1996). Component probabilities and the conjunction fallacy: Resolving signed summation and the low component model in a contingent approach. Acta Psychologica, 94(1), 1-20. doi:10.1016/0001-6918(95)00048-8

Fisk, J. E., \& Pidgeon, N. (1998). Conditional probabilities, potential surprise, and the conjunction fallacy. Quarterly Journal of Experimental Psychology Section A: Human Experimental Psychology, 51A(3), 655-681. doi:10.1080/027249898391576

French, C. C. \& Stone, A. (2014). Anomalistic psychology: Exploring paranormal belief and experience. Basingstoke: Palgrave

Gallagher, C., Kumar, V., K. \& Pekula, R., J. (1994). The anomalous experiences inventory: reliability and validity. Journal of Parapsychology, 58(4), 402-428.

Greenwood, S. \& Airey, R. (2009). The complete illustrated encyclopedia of witchcraft and practical magic. London: Hermes House

Hadlaczky, G. \& Westerlund, J. (2011). Sensitivity to coincidences and paranormal belief. Perceptual \& Motor Skills, 113(3), 894-908. doi: 10.2466/09.22.PMS.113.6.894-908 ISSN $0031-5125$

Irwin, H. J. (2009). The psychology of paranormal belief: A researcher's handbook. Hatfield, Hertfordshire: University of Hertfordshire Press

Irwin, H. J., (2015). Thinking style and the making of a paranormal disbelief. Journal of the Society for Psychical Research, 79.3(920), 129-139

Irwin, H. J., Dagnall, N. \& Drinkwater, K. (2017). Tweedledum and Tweedledee: Are paranormal disbelievers a mirror image of believers? Journal of the Society for Psychical Research, 81(3), 161-179

Irwin, H. J. \& Watt, C. A. (2007). An introduction to parapsychology (5th edition). Jefferson, NC, US: McFarland 
Irwin, H. J., \& Wilson, K. (2013). Anomalous experiences and the intuitive-experiential style of thinking. Journal of the Society for Psychical Research, 77.2(911), 65-71

Kahneman D. (2011). Thinking, Fast and Slow. London, UK: Penguin

Koehler, J. J. (1993). The influence of prior beliefs on scientific judgments of evidence quality. Organizational Behavior \& Human Decision Processes, 56(1), 28-55. doi:10.1006/obhd.1993.1044

Krippner, S. \& Friedman, H.L. (2010). Debating psychic experience: Human potential or human illusion? Santa Barbara, CA: Praeger.

Liberali, J. M., Reyna, V. F., Furlan, S., Stein, L. M., \& Pardo, S. T. (2012). Individual differences in numeracy and cognitive reflection, with implications for biases and fallacies in probability judgment. Journal of Behavioral Decision Making, 25(4), 361-381. doi: $10.1002 / \mathrm{bdm} .752$.

Locksley, A., \& Stangor, C. (1984). Why versus how often: Causal reasoning and the incidence of judgmental bias. Journal of Experimental Social Psychology, 20(5), 470-483. doi:10.1016/0022-1031(84)90038-6

Lottoland (2016). UK Lotto or EuroMillions: Compare your winning chances. Available online via https://www.lottoland.co.uk/magazine/uk-lotto-or-euromillions-compare-yourwinning-chances.html [Accessed 01 July 2017]

MacCallum, R. C., Zhang, S., Preacher, K.J. \& Rucker, D.D. (2002). On the practice of dichotomization of quantitative variables. Psychological Methods, 7(1), 19-40. doi: 10.1037//1082-989X.7.1.19

Msaouel, P., Kappos, T., Tasoulis, A., Apostolopoulos, A. P., Lekkas, I., Tripodaki, E., \& Keramaris, N. C. (2014). Assessment of cognitive biases and biostatistics knowledge of medical residents: A multicenter, cross-sectional questionnaire study. Medical Education Online, 19. doi:10.3402/meo.v19.23646 
Narum, S.R. (2006). Beyond Bonferroni: Less conservative analyses for conservation genetics. Conservation Genetics, 7(5), 783-787. doi 10.1007/s10592-005-9056-y

Norušis, M.J. (2007). SPSS 15.0 Advanced Statistical Procedures Companion. Upper Saddle River, NJ: Prentice Hall

Otis, L. P., \& Alcock, J. E. (1982). Factors affecting extraordinary belief. Journal of Social Psychology, 118(1), 77-85. doi:10.1080/00224545.1982.9924420

Pizzagalli, D. D., Lehmann, D. D., \& Brugger, P. P. (2001). Lateralized direct and indirect semantic priming effects in subjects with paranormal experiences and beliefs. Psychopathology, 34(2), 75-80. doi:10.1159/000049284.

Powell, D. H. (2009). The ESP enigma: The scientific case for psychic phenomena. New York, US: Walker Publishing

Prike, T., Arnold, M. M. \& Williamson, P. (2017). Psychics, aliens, or experience? Using the Anomalistic Belief Scale to examine the relationship between type of belief and probabilistic reasoning. Consciousness \& Cognition 53, 151-164 · doi: 10.1016/j.concog.2017.06.003

Roe, C. A. (1999). Critical thinking and belief in the paranormal: A re-evaluation. British Journal of Psychology, 90(1), 85-98. doi:10.1348/000712699161288

Rhine-Feather, S. \& Schmicker, M. (2005). The gift: ESP, the extraordinary experiences of ordinary people. London, UK: Rider.

Rogers, P., (2014). The probabilistic reasoning bias hypothesis of belief in the paranormal: A review. In N. Galbraith (Ed.). Aberrant beliefs and thinking. Hove, UK: Psychology Press. Rogers, P. Davis, T. \& Fisk, J. (2009). Paranormal belief and susceptibility to the conjunction fallacy. Applied Cognitive Psychology, 23(4), 524-542. doi:10.1002/acp.1472 
Rogers, P., Fisk, J. E. \& Lowrie, E. L. (2016). Paranormal believers' susceptibility to errors for confirmatory vs. disconfirmatory conjunctions. Applied Cognitive Psychology. doi: 10.1002/acp.3222

Rogers, P. Fisk, J. \& Wiltshire, D. (2011). Paranormal belief and the conjunction fallacy: Controlling for temporal relatedness and potential surprise differentials in component events. Applied Cognitive Psychology, 24, 1-20. doi: 10.1002/acp.1732

Rogers, P. Qualter, P \& Wood, D. (2016). The impact of event vividness, event severity and prior paranormal belief on attributions toward a depicted remarkable coincidence experience: Two studies examining the misattribution hypothesis. British Journal of Psychology, doi:10.1111/bjop.12173

Shackle, G. L. S. (1969). Decision, order and time in human affairs. Cambridge, UK: Cambridge University Press

Shermer, M. (2011). The believing brain: From ghosts and Gods to politics and conspiracies. How we construct beliefs and reinforce them as truths. New York, US: Times Books/Henry Holt \& Co.

Tentori, K., Crupi, V. \& Russo, S. (2013). On the determinants of the conjunction fallacy: probability verses inductive confirmation. Journal of Experimental Psychology: General, 142(1), 235-255. doi: 10.1037/a0028770

Thalbourne, M. A. (1996). Belief in life after death: psychological origins and influences. Personality \& Individual Differences, 21(6), 1043-1045. doi:10.1016/S01918869(96)00167-5

Thalbourne, M. A. (2010). The Australian Sheep-Goat Scale: Development and empirical findings. Australian Journal of Parapsychology, 10(1), 5-39

Thalbourne, M. A. \& Delin. P. S (1993). A new instrument for measuring the sheep-goat variable: Its psychometric properties and factor structure. Journal of Society for Psychical 
Research, 59(832), 172-186

Thüring, M., \& Jungermann, H. (1990). The conjunction fallacy: Causality vs. event probability. Journal of Behavioral Decision Making, 3(1), 61-74.

doi:10.1002/bdm.3960030106

Tversky, A. \& Kahneman, D. (1982). Judgments of and by representativeness. In D.

Kahneman, P. Slovic \& A. Tversky (Eds.) Judgment under uncertainty: Heuristics and biases (pp. 84-98). Cambridge, UK: Cambridge University Press

Tversky, A. \& Kahneman, D. (1983). Extensional versus intuitive reasoning: The conjunction fallacy in probability judgment. Psychological Review, 90(4), 293-315. doi: 10.1037/0033295X.90.4.293

Twisk, J. W. R. (2006). Applied multilevel analysis: A practical guide. Cambridge, UK: Cambridge University Press

Wiseman, R. \& Watt, C. (2006). Belief in psychic ability and the misattribution hypothesis: A qualitative review. British Journal of Psychology, 97(3), 323-338. doi: $10.1348 / 000712605 \times 72523$

Yates, J., E. \& Carlson, B., W. (1986). Conjunction errors: Evidence for multiple judgments procedures including "signed summation". Organizational Behavior \& Human Decision Processes, 37(2), 230-253. doi:10.1016/0749-5978(86)90053-1 


\section{Acknowledgments}

The authors are grateful to Prof. G. Dave Garson and Dr. Cecilia Ma for their advice regarding GLMM, and to two anonymous reviewers for their comments on an earlier draft of this paper.

\section{Funding}

This research did not receive any specific grant from funding agencies in the public, commercial, or not-for-profit sectors. 
Table 1: Summary of Three Conjunction Fallacy Accounts ${ }^{\dagger}$

\begin{tabular}{|c|c|c|c|c|}
\hline Account & Focus on constituents' & $\begin{array}{l}\text { Constituent } \\
\text { Relatedness }\end{array}$ & Key Determinant(s) of Conjunction Error Generation & Applicable to which combinations \\
\hline $\mathrm{M} \rightarrow \mathrm{A}$ & representativeness & -- & more likely of first vs. second constituent $[p(\mathrm{~A})$ or $p(\mathrm{~B})]$ & common although mostly $\mathrm{L} / \mathrm{U}$ \\
\hline \multirow[t]{3}{*}{$\mathrm{A} \rightarrow \mathrm{B}$} & conditional relatedness & unrelated & as for $\mathrm{M} \rightarrow \mathrm{A}$ paradigm & as for $\mathrm{M} \rightarrow \mathrm{A}$ paradigm \\
\hline & & positive & presence / strength of constituent relatedness & common for $\mathrm{L} / \mathrm{U}, \mathrm{L} / \mathrm{U}, \mathrm{UL}$ and $\mathrm{U} / \mathrm{U}$ \\
\hline & & negative & conjunction errors rare & -- \\
\hline \multirow[t]{3}{*}{ PSV } & surprisingness & unrelated & less likely of first vs. second constituent [p(A) vs. $p(\mathrm{~B})]$ & $\mathrm{L} / \mathrm{U}, \mathrm{L} / \mathrm{U}, \mathrm{UL}$ and $\mathrm{U} / \mathrm{U}$ \\
\hline & & positive & less likely of second constituent vs. second constituent given first $[p(\mathrm{~B})$ vs. $p(\mathrm{~B} \backslash \mathrm{A})]$ & $\mathrm{L} / \mathrm{U}, \mathrm{L} / \mathrm{U}, \mathrm{UL}$ and $\mathrm{U} / \mathrm{U}$ \\
\hline & & negative & conjunctive probability estimates too low for $\mathrm{CE}$ generation & -- \\
\hline
\end{tabular}

${ }^{\dagger} \mathrm{M} \rightarrow \mathrm{A}$ and A $\rightarrow$ B accounts from Tversky and Kahneman (1983); Potential Surprise Value (PSV) account from Fisk (2002; Fisk \& Pidgeon, 1998); likely/likely (L/L), likely/unlikely (L/U), unlikely/likely (U/L) and unlikely/ unlikely (U/U) constituent combinations 
Table 2: Probability estimates for each scenario by constituent relatedness type ${ }^{\dagger}$

\begin{tabular}{|c|c|c|c|c|c|c|c|c|c|c|c|c|c|c|c|}
\hline \multirow{2}{*}{\multicolumn{2}{|c|}{ Scenario }} & \multirow{2}{*}{$\begin{array}{l}\text { Statement } \\
\text { Type }\end{array}$} & \multicolumn{6}{|c|}{ Conditionally Unrelated } & \multicolumn{7}{|c|}{ Positively Conditionally Unrelated } \\
\hline & & & $M$ & $(S D)$ & $t$ & $d f$ & $p$ & $d$ & $M$ & $(S D)$ & $t$ & $d f$ & $p$ & & $\vec{d}$ \\
\hline \multirow[t]{2}{*}{01.} & inherit $\checkmark$ & (b) alone & 30.0 & $(25.2)$ & .53 & 16 & .301 & .17 & 30.1 & $(28.8)$ & -2.81 & 17 & .006 & $* *$ & -1.04 \\
\hline & & (b) given (a) & 25.6 & $(24.5)$ & & & & & 50.6 & $(27.8)$ & & & & & \\
\hline \multirow[t]{2}{*}{02.} & career $\checkmark$ & (b) alone & 37.3 & $(16.7)$ & -.80 & 17 & .217 & -.18 & 35.6 & $(18.4)$ & -3.50 & 16 & .015 & $*$ & -1.36 \\
\hline & & (b) given (a) & 40.8 & $(22.1)$ & & & & & 53.5 & (18.7) & & & & & \\
\hline \multirow[t]{2}{*}{03.} & football & (b) alone & 33.1 & (26.6) & -.46 & 17 & .327 & -.11 & 48.8 & $(30.7)$ & -.57 & 16 & .288 & & -.21 \\
\hline & & (b) given (a) & 36.0 & (24.9) & & & & & 54.4 & $(23.0)$ & & & & & \\
\hline \multirow[t]{2}{*}{04 . } & house $\checkmark$ & (b) alone & 52.6 & $(28.1)$ & .11 & 16 & .457 & .03 & 35.8 & $(27.2)$ & -2.34 & 17 & .016 & $*$ & -.67 \\
\hline & & (b) given (a) & 51.8 & $(24.0)$ & & & & & 52.8 & $(23.7)$ & & & & & \\
\hline \multirow[t]{2}{*}{05.} & motorway & (b) alone & 41.1 & (26.8) & .40 & 17 & .347 & .11 & 31.4 & $(27.5)$ & -.89 & 17 & .194 & & -.17 \\
\hline & & (b) given (a) & 38.3 & $(24.0)$ & & & & & 36.1 & $(28.4)$ & & & & & \\
\hline \multirow[t]{2}{*}{06.} & gliding & (b) alone & 61.1 & (21.8) & 1.60 & 17 & .065 & .51 & 63.8 & $(24.8)$ & .09 & 16 & .931 & & .03 \\
\hline & & (b) given (a) & 48.6 & $(27.2)$ & & & & & 63.2 & $(17.3)$ & & & & & \\
\hline \multirow[t]{2}{*}{07.} & woman $\checkmark$ & (b) alone & 40.2 & (22.8) & -1.14 & 16 & .130 & -.33 & 37.7 & (21.8) & -1.95 & 17 & .034 & $*$ & -.75 \\
\hline & & (b) given (a) & 48.0 & $(24.5)$ & & & & & 51.1 & $(22.5)$ & & & & & \\
\hline \multirow[t]{2}{*}{08.} & watch & (b) alone & 53.9 & (28.7) & .18 & 17 & .429 & .06 & 65.8 & (20.1) & -1.48 & 17 & .079 & & -.42 \\
\hline & & (b) given (a) & 52.2 & (31.4) & & & & & 74.4 & $(20.7)$ & & & & & \\
\hline
\end{tabular}

$\dagger$ Significant at the $* p<.05 * * p<.01$ levels (one-tailed; $n=54$ ). Scenarios marked with a tick $(\checkmark)$ retained 
Table 2: Probability estimates for each scenario by constituent relatedness type (continued) ${ }^{\dagger}$

\begin{tabular}{|c|c|c|c|c|c|c|c|c|c|c|c|c|c|c|c|c|}
\hline \multirow{2}{*}{\multicolumn{2}{|c|}{ Scenario }} & \multirow{2}{*}{$\begin{array}{l}\text { Statement } \\
\text { Type }\end{array}$} & \multicolumn{7}{|c|}{ Conditionally Unrelated } & \multicolumn{7}{|c|}{ Positively Conditionally Unrelated } \\
\hline & & & $M$ & $(S D)$ & $t$ & $d f$ & $p$ & & $d$ & $M$ & $(S D)$ & $t$ & $d f$ & $p$ & & $d$ \\
\hline \multirow[t]{2}{*}{09.} & horse $\checkmark$ & (b) alone & 35.6 & $(30.2)$ & 1.77 & 17 & .048 & $*$ & .32 & 31.5 & $(18.5)$ & -1.72 & 16 & .024 & $*$ & -.59 \\
\hline & & (b) given (a) & 27.2 & $(21.8)$ & & & & & & 44.1 & $(23.9)$ & & & & & \\
\hline \multirow[t]{2}{*}{10.} & husband & (b) alone & 43.4 & $(28.9)$ & 1.03 & 16 & .159 & & .32 & 38.9 & $(34.5)$ & -.02 & 17 & .493 & & -.01 \\
\hline & & (b) given (a) & 34.8 & $(23.6)$ & & & & & & 39.1 & (29.6) & & & & & \\
\hline \multirow[t]{2}{*}{11.} & sleep $\checkmark$ & (b) alone & 25.8 & $(22.4)$ & .28 & 17 & .391 & & .09 & 33.9 & $(32.1)$ & -2.13 & 17 & .024 & $*$ & -.48 \\
\hline & & (b) given (a) & 23.7 & $(23.8)$ & & & & & & 48.2 & $(27.4)$ & & & & & \\
\hline \multirow[t]{2}{*}{12.} & mill & (b) alone & 30.8 & (26.6) & 1.04 & 17 & .156 & & .26 & 50.3 & (19.3) & 1.17 & 15 & .130 & & .41 \\
\hline & & (b) given (a) & 24.4 & $(21.6)$ & & & & & & 43.4 & (13.9) & & & & & \\
\hline \multirow[t]{2}{*}{13.} & stomach & (b) alone & 47.5 & (18.4) & -.30 & 15 & .384 & & -.05 & 43.6 & $(34.2)$ & .08 & 17 & .469 & & .02 \\
\hline & & (b) given (a) & 48.4 & $(20.5)$ & & & & & & 42.8 & $(30.8)$ & & & & & \\
\hline \multirow[t]{2}{*}{14.} & murder $\checkmark$ & (b) alone & 37.4 & $(22.2)$ & .30 & 17 & .384 & & .06 & 47.5 & (18.5) & -3.24 & 15 & .003 & $* *$ & -1.39 \\
\hline & & (b) given (a) & 35.9 & $(25.4)$ & & & & & & 64.7 & $(17.5)$ & & & & & \\
\hline & marrow $\checkmark$ & (b) alone & 43.6 & (20.7) & 1.51 & 17 & .076 & & .34 & 57.4 & $(22.4)$ & -2.98 & 17 & .004 & $* *$ & -.85 \\
\hline & & (b) given (a) & 36.9 & $(18.1)$ & & & & & & 69.2 & (19.6) & & & & & \\
\hline \multirow[t]{2}{*}{16.} & pregnant $\checkmark$ & (b) alone & 34.4 & (21.4) & -1.65 & 15 & .059 & & -.52 & 27.6 & (28.4) & -3.98 & 16 & $<.001$ & $* *$ & -1.22 \\
\hline & & (b) given (a) & 47.2 & $(27.4)$ & & & & & & 52.4 & $(28.7)$ & & & & & \\
\hline
\end{tabular}

$\dagger$ Significant at the * $p<.05 * * p<.01$ levels (one-tailed; $n=54$ ). Scenarios marked with a tick $(\checkmark)$ retained 
Table 3: Internal Reliability, Descriptive, Normality \& Skew Statistics for Paranormal Belief Subscales ${ }^{\dagger}$

\begin{tabular}{|c|c|c|c|c|c|c|c|c|c|c|c|c|c|}
\hline \multirow{2}{*}{$\begin{array}{l}\text { Belief } \\
\text { Type }\end{array}$} & \multirow{2}{*}{$\frac{\text { Reliability }}{\alpha}$} & \multicolumn{4}{|c|}{ Descriptives } & \multicolumn{4}{|c|}{ Normality } & \multicolumn{4}{|c|}{ Skew } \\
\hline & & $M$ & $(S D)$ & Obs Range & Median & $K-S$ & $(d f)$ & $p$ & & $I S$ & $(S E)$ & $Z$ & \\
\hline ESP & .92 & 3.65 & (1.49) & $1.00-6.10$ & 3.80 & .08 & (129) & .055 & $a$ & -.23 & $(.22)$ & -1.03 & \\
\hline PK & .89 & 2.68 & (1.48) & $1.00-6.25$ & 2.25 & .14 & (129) & $<.001$ & $* * *$ & .47 & $(.22)$ & 2.10 & $*$ \\
\hline LAD & .79 & 3.76 & (1.74) & $1.00-7.00$ & 4.00 & .10 & (129) & .003 & $* *$ & -.14 & $(.22)$ & -.61 & \\
\hline
\end{tabular}

${ }^{\dagger}$ Reliability given by Cronbach’s alpha $(\alpha)$ coefficient; potential ranges 1:00 to 7:00; normality indicated by Kolmogorov-Smirnov $(K-S)$ tests; sig. effects at the *p<.05 **p<.01 and $* * *$ p $<.001$ levels; $a=$ approaches significance (two-tailed; $n=121$ ). 
Table 4: Mean Probability Estimates \& Percentage of Conjunction Errors by Constituent Relatedness Type \& Scenario ${ }^{\dagger}$

\begin{tabular}{|c|c|c|c|c|c|c|c|c|c|}
\hline \multirow{2}{*}{\multicolumn{2}{|c|}{ Scenario }} & \multirow{2}{*}{$\begin{array}{l}\text { Relatedness } \\
\text { Type }\end{array}$} & \multicolumn{2}{|c|}{ First Constituent } & \multicolumn{2}{|c|}{ Second Constituent } & \multicolumn{2}{|c|}{ Conjunction } & \multirow{2}{*}{$\begin{array}{c}\text { CEs } \\
\%\end{array}$} \\
\hline & & & $M$ & $S D$ & $M$ & $S D$ & $M$ & $S D$ & \\
\hline \multirow[t]{3}{*}{1.} & Inheritance & Unrelated & 38.39 & (30.18) & 24.43 & $(21.74)$ & 18.63 & $(22.60)$ & 26.8 \\
\hline & & Related & 33.09 & $(25.88)$ & 30.38 & $(24.39)$ & 28.28 & $(28.77)$ & 31.3 \\
\hline & & All & 35.57 & $(27.98)$ & 27.60 & $(23.28)$ & 23.78 & $(26.41)$ & 29.2 \\
\hline \multirow[t]{3}{*}{2.} & Career & Unrelated & 65.27 & $(30.80)$ & 31.00 & $(23.53)$ & 26.75 & $(24.53)$ & 21.9 \\
\hline & & Related & 39.70 & $(23.77)$ & 28.21 & $(20.78)$ & 24.02 & $(21.24)$ & 35.7 \\
\hline & & All & 53.33 & $(30.45)$ & 29.70 & $(22.24)$ & 25.48 & $(23.00)$ & 28.3 \\
\hline \multirow[t]{3}{*}{3.} & House & Unrelated & 55.66 & (33.33) & 28.96 & $(25.90)$ & 25.05 & $(23.86)$ & 35.7 \\
\hline & & Related & 45.42 & $(26.43)$ & 34.39 & $(26.37)$ & 29.66 & $(28.44)$ & 32.8 \\
\hline & & All & 50.20 & $(30.16)$ & 31.86 & (26.19) & 27.51 & $(26.40)$ & 34.2 \\
\hline \multirow[t]{3}{*}{4.} & Woman & Unrelated & 16.75 & $(24.10)$ & 26.68 & $(25.51)$ & 21.93 & $(25.17)$ & 55.4 \\
\hline & & Related & 58.00 & $(23.41)$ & 37.77 & $(27.63)$ & 43.38 & $(30.91)$ & 51.6 \\
\hline & & All & 38.75 & (31.39) & 32.59 & $(27.12)$ & 33.37 & $(30.23)$ & 53.3 \\
\hline \multirow[t]{3}{*}{5.} & Sleep & Unrelated & 18.09 & (23.11) & 34.48 & (33.08) & 14.72 & (19.29) & 26.6 \\
\hline & & Related & 53.13 & $(30.75)$ & 40.91 & $(28.27)$ & 44.09 & $(32.90)$ & 51.8 \\
\hline & & All & 34.44 & (32.06) & 37.48 & (30.97) & 28.43 & $(30.23)$ & 38.3 \\
\hline \multirow[t]{3}{*}{6.} & Murder & Unrelated & 27.36 & $(23.41)$ & 31.59 & $(25.51)$ & 25.19 & (25.78) & 32.8 \\
\hline & & Related & 55.88 & $(28.12)$ & 31.07 & $(27.02)$ & 40.61 & $(32.45)$ & 50.0 \\
\hline & & All & 40.67 & $(29.32)$ & 31.35 & $(26.11)$ & 32.38 & (29.97) & 40.8 \\
\hline \multirow[t]{3}{*}{7.} & Marrow & Unrelated & 45.97 & $(31.60)$ & 41.19 & (27.74) & 35.20 & $(28.51)$ & 39.1 \\
\hline & & Related & 35.38 & $(22.55)$ & 35.34 & $(24.46)$ & 35.50 & $(28.76)$ & 53.6 \\
\hline & & All & 41.03 & (28.14) & 38.46 & $(26.31)$ & 35.34 & $(28.51)$ & 45.8 \\
\hline \multirow[t]{3}{*}{8.} & Pregnant & Unrelated & 40.52 & (32.37) & 30.93 & (27.39) & 27.52 & (27.48) & 35.7 \\
\hline & & Related & 29.20 & $(29.42)$ & 27.31 & $(26.16)$ & 22.27 & (26.66) & 39.1 \\
\hline & & All & 34.48 & $(31.22)$ & 29.00 & $(26.69)$ & 24.72 & $(27.06)$ & 37.5 \\
\hline \multirow[t]{3}{*}{--} & Mean & Unrelated & 38.55 & (32.91) & 31.39 & (26.81) & 24.45 & (25.31) & 34.0 \\
\hline & & Related & 43.45 & (28.14) & 32.99 & (25.80) & 33.16 & (29.74) & 42.9 \\
\hline & & All & 41.00 & $(30.70)$ & 32.18 & $(26.31)$ & 28.80 & (27.94) & 38.4 \\
\hline
\end{tabular}

${ }^{\dagger}$ For conditionally unrelated events, probability estimates for the first constituent are denoted by $p(\mathrm{~A})$, for the second constituent by $p(\mathrm{~B})$ and for the conjunctive term by $p(\mathrm{~A} \& \mathrm{~B})$. For positively conditionally related events estimates for the first constituent are denoted by $p(\mathrm{~A})$, for the second constituent by $p(\mathrm{~B} \backslash \mathrm{A})$ and for the conjunctive term by $p(\mathrm{~A} \& \mathrm{~B} \backslash \mathrm{A})$; potential ranges $0-100(n=120)$. 
Table 5: Descriptive, Normality \& Skew Statistics for Mean Number of Conjunction Errors by Relatedness Type ${ }^{\dagger}$

\begin{tabular}{|c|c|c|c|c|c|c|c|c|c|c|c|c|}
\hline \multirow{2}{*}{$\begin{array}{l}\text { Relatedness } \\
\text { Type }\end{array}$} & \multicolumn{4}{|c|}{ Descriptives } & \multicolumn{4}{|c|}{ Normality } & \multicolumn{4}{|c|}{ Skew } \\
\hline & $M$ & $(S D)$ & Obs Range & Median & $K-S$ & $(d f)$ & $p$ & & $I S$ & $(S E)$ & $Z$ & \\
\hline Related & 1.72 & (1.23) & $1.00-4.00$ & 2.00 & .21 & (120) & $<.001$ & $* * *$ & .37 & .22 & 1.64 & \\
\hline Unrelated & 1.36 & (1.24) & $1.00-4.00$ & 1.00 & .22 & (120) & $<.001$ & $* * *$ & .63 & .22 & 2.82 & $* *$ \\
\hline All & 3.08 & (1.92) & $1.00-8.00$ & 3.00 & .12 & (120) & $<.001$ & $* * *$ & .24 & .22 & 1.05 & \\
\hline
\end{tabular}

†Potential range for positively conditionally related \& conditionally unrelated types $0-4$; potential range for all 0-8; normality given by Kolmogorov-Smirnov $(K-S)$ tests; sig. effects at the $* \mathrm{p}<.05 * * \mathrm{p}<.01$ and $* * * \mathrm{p}<.001$ levels; $a=$ approaches significance (two-tailed; $n=121$ ). 
Table 6: Correlations $(r)$ between Paranormal Belief Types, Respondent Demographics \& Mean Number of Conjunction Errors ${ }^{\dagger}$

\begin{tabular}{|c|c|c|c|c|c|c|c|c|c|c|c|c|c|c|c|c|c|c|c|c|c|}
\hline \multirow{2}{*}{ ESP beliefs } & \multicolumn{2}{|c|}{$\begin{array}{c}\text { ESP } \\
\text { beliefs }\end{array}$} & \multicolumn{2}{|c|}{$\begin{array}{c}\text { PK } \\
\text { beliefs }\end{array}$} & \multicolumn{2}{|c|}{$\begin{array}{c}\text { LAD } \\
\text { beliefs }\end{array}$} & \multicolumn{2}{|c|}{ Gender } & \multicolumn{2}{|c|}{ Age } & \multicolumn{2}{|c|}{ Ethnicity } & \multirow[t]{2}{*}{ Occup } & \multicolumn{2}{|c|}{$\begin{array}{c}\text { Quals } \\
\text { (general) }\end{array}$} & \multirow[t]{2}{*}{$\begin{array}{l}\text { Quals } \\
(\mathrm{m} / \mathrm{s} / \mathrm{p})\end{array}$} & \multicolumn{2}{|c|}{$\begin{array}{c}\text { CEs } \\
\text { (related) }\end{array}$} & \multicolumn{2}{|c|}{$\begin{array}{c}\text { CEs } \\
\text { (unrelated) } \\
\end{array}$} & \multirow[t]{2}{*}{$\begin{array}{l}\text { CEs } \\
\text { (all) } \\
\end{array}$} \\
\hline & & & & & & & & & & & & & & & & & & & & & \\
\hline PK beliefs & .70 & $* * *$ & & & & & & & & & & & & & & & & & & & \\
\hline LAD beliefs & .79 & $* * *$ & .62 & $* * *$ & & & & & & & & & & & & & & & & & \\
\hline Gender $^{\dagger}$ & .10 & & .15 & & .14 & & & & & & & & & & & & & & & & \\
\hline Age & -.16 & & -.13 & & -.07 & & -.14 & & & & & & & & & & & & & & \\
\hline Ethnicity $^{\dagger}$ & -.22 & $*$ & -.09 & & -.15 & & .05 & & .10 & & & & & & & & & & & & \\
\hline Occupation $^{\dagger}$ & .00 & & .02 & & .07 & & .19 & $*$ & -.51 & $* * *$ & .07 & & & & & & & & & & \\
\hline Quals (general) & -.09 & & .01 & & -.27 & $* *$ & -.09 & & .00 & & .04 & & -.03 & & & & & & & & \\
\hline Quals (m/s/p) & -.13 & & -.06 & & -.25 & $* *$ & -.14 & & -.09 & & -.22 & $*$ & -.01 & .57 & $* * *$ & & & & & & \\
\hline CEs (related) & .14 & & .19 & $*$ & .14 & & -.06 & & -.01 & & -.03 & & -.02 & -.25 & $* *$ & -.17 & & & & & \\
\hline CEs (unrelated) & .09 & & .15 & & .14 & & .15 & & -.09 & & -.12 & & .11 & -.24 & $*$ & -.08 & .21 & $*$ & & & \\
\hline CEs (all) & .15 & & .22 & $*$ & .18 & & .06 & & -.07 & & -.09 & & .06 & -.32 & $* *$ & -.17 & .78 & $* * *$ & .77 & $* * *$ & \\
\hline
\end{tabular}

${ }^{\dagger}$ Mean CEs for positively conditionally related, conditionally unrelated and all constituent pairs respectively. Dichotomous measures where higher scores reflect female gender, Caucasian ethnicity and student occupational status; $\mathrm{m} / \mathrm{s} / \mathrm{p}$ refers to math/statistics/psychology qualifications. Coefficients for one dichotomous measure reflect $\mathrm{r}_{\mathrm{b}}$; coefficients for two dichotomous measures reflect $p$ hi; sig. effects at the * $\mathrm{p}<.05$ $* * \mathrm{p}<.01$ and $* * * \mathrm{p}<.001$ levels (two-tailed; $n=108-120$ ) 
Table 7: Percentage of Conjunction Errors, Non-Errors \& Responses Correctly Predicted by Paranormal Belief \& Intercept Types ${ }^{\dagger}$

\begin{tabular}{|c|c|c|c|c|}
\hline Response & Intercept & ESP & PK & LAD \\
\hline Type & Type & $(\%)$ & $(\%)$ & $(\%)$ \\
\hline \multirow[t]{2}{*}{ Errors } & Fixed & 20.0 & 23.1 & 18.5 \\
\hline & Random & 41.2 & 39.7 & 42.2 \\
\hline \multirow[t]{2}{*}{ Non-errors } & Fixed & 90.3 & 88.3 & 87.9 \\
\hline & Random & 88.7 & 88.8 & 87.7 \\
\hline \multirow[t]{2}{*}{ All } & Fixed & 63.8 & 63.7 & 61.8 \\
\hline & Random & 70.8 & 70.3 & 70.6 \\
\hline
\end{tabular}

${ }^{\dagger}$ Random intercept full models with first order auto-regressive (AR1) covariance structure ; figures to 1 decimal place; $n=863$ cases 
Table 8: Predictors of Conjunction Error Generation (Yes vs. No) by Paranormal Belief Type ${ }^{\dagger}$

\begin{tabular}{|c|c|c|c|c|c|c|c|c|c|c|c|c|c|c|c|c|c|c|c|c|c|}
\hline \multirow[b]{3}{*}{ Predictor } & \multicolumn{7}{|c|}{ ESP } & \multicolumn{7}{|c|}{ PK } & \multicolumn{7}{|c|}{ LAD } \\
\hline & \multirow[b]{2}{*}{$b$} & \multirow[b]{2}{*}{$t$} & \multirow[b]{2}{*}{$p$} & & \multirow[b]{2}{*}{$\exp (b)$} & \multicolumn{2}{|c|}{$95 \% C I$} & \multirow[b]{2}{*}{$b$} & \multirow[b]{2}{*}{$t$} & \multirow[b]{2}{*}{$p$} & & \multirow[b]{2}{*}{$\exp (b)$} & \multicolumn{2}{|c|}{$95 \% C I$} & \multirow[b]{2}{*}{$b$} & \multirow[b]{2}{*}{$t$} & \multirow[b]{2}{*}{$p$} & & \multirow[b]{2}{*}{$\exp (b)$} & \multicolumn{2}{|c|}{$95 \% C I$} \\
\hline & & & & & & Lwr & Upr & & & & & & Lwr & Upr & & & & & & Lwr & Upr \\
\hline Random Intercept & -.83 & -6.27 & $<.001$ & $* * *$ & .43 & .33 & .56 & -.84 & -6.41 & $<.001$ & $* * *$ & .43 & .34 & .56 & -.80 & -6.13 & $<.001$ & $* * *$ & .45 & .35 & .58 \\
\hline Belief & .13 & 1.40 & .161 & & 1.13 & .95 & 1.36 & .23 & 2.67 & .008 & $* *$ & 1.26 & 1.06 & 1.49 & .08 & .99 & .325 & & 1.08 & .93 & 1.25 \\
\hline Relatedness & .49 & 3.25 & .001 & $* *$ & 1.63 & 1.21 & 2.18 & .48 & 3.23 & .001 & $* *$ & 1.61 & 1.21 & 2.15 & .44 & 3.04 & .002 & $* *$ & 1.56 & 1.17 & 2.07 \\
\hline Belief x Related & -.01 & -.09 & .931 & & .99 & .81 & 1.21 & -.06 & -.56 & .573 & & .95 & .78 & 1.15 & .01 & .16 & .870 & & 1.01 & .86 & 1.19 \\
\hline More Likely (ML) & .00 & .69 & .490 & & 1.00 & 1.00 & 1.01 & .00 & .71 & .477 & & 1.00 & 1.00 & 1.01 & .00 & .62 & .534 & & 1.00 & 1.00 & 1.01 \\
\hline Less Likely (LL) & -.02 & -2.27 & .024 & $*$ & .99 & .97 & 1.00 & -.02 & -2.39 & .017 & $*$ & .98 & .97 & 1.00 & -.01 & -2.04 & .042 & $*$ & .99 & .98 & 1.00 \\
\hline Belief x ML & .00 & .91 & .365 & & 1.00 & 1.00 & 1.01 & -.00 & -.70 & .486 & & 1.00 & .99 & 1.00 & .00 & .57 & .572 & & 1.00 & 1.00 & 1.01 \\
\hline Belief x LL & .00 & .01 & .993 & & 1.00 & .99 & 1.01 & .00 & .68 & .496 & & 1.00 & 1.00 & 1.01 & -.01 & -1.28 & .201 & & 1.00 & .99 & 1.00 \\
\hline ML x Relatedness & .01 & 1.25 & .212 & & 1.01 & 1.00 & 1.02 & .01 & 1.07 & .284 & & 1.01 & 1.00 & 1.02 & .01 & 1.06 & .291 & & 1.01 & .99 & 1.02 \\
\hline LL x Relatedness & .01 & 1.19 & .236 & & 1.01 & .99 & 1.03 & .01 & 1.48 & .140 & & 1.01 & 1.00 & 1.03 & .01 & 1.27 & .203 & & 1.01 & .99 & 1.03 \\
\hline Belief $x$ ML $x$ Relate & .00 & .32 & .749 & & 1.00 & .99 & 1.01 & .01 & 1.52 & .129 & & 1.01 & 1.00 & 1.01 & -.00 & -.78 & .436 & & 1.00 & .99 & 1.00 \\
\hline Belief x LL x Relate & -.00 & -.24 & .809 & & 1.00 & .99 & 1.01 & -.00 & -.77 & .441 & & 1.00 & 1.00 & 1.01 & .01 & 1.06 & .289 & & 1.01 & 1.00 & 1.01 \\
\hline Gen. Qualifications & -.31 & -3.64 & $<.001$ & $* * *$ & .74 & .63 & .87 & -.32 & -3.89 & $<.001$ & $* * *$ & .73 & .62 & .85 & -.27 & -3.07 & .002 & $* *$ & .77 & .65 & .91 \\
\hline AR1 Diagonal ${ }^{\ddagger}$ & .91 & 18.49 & $<.001$ & $* * *$ & -- & .82 & 1.01 & .91 & 18.46 & $<.001$ & $* * *$ & -- & .82 & 1.01 & .91 & 18.46 & $<.001$ & $* * *$ & -- & .82 & 1.01 \\
\hline AR1 Rho & .04 & .96 & .337 & & -- & -.04 & .13 & .05 & 1.06 & .288 & & -- & -.04 & .13 & .05 & 1.04 & .297 & & -- & -.04 & .13 \\
\hline
\end{tabular}

${ }^{\dagger}$ All non-dichotomous predictors grand mean centered; full models with first order auto-regressive (AR1) covariance structure; odds rations given by exp( $\left.b\right)$ coefficients; figures to 2 decimal places; sig. effects at the $* p<.05 * * p<.01$ and ${ }^{* * *} p<.001$ levels (two-tailed; $n=863$ cases); inferential statistic for ARl Rho (intraclass correlation coefficient) and ARI Diagonal (estimated variance) is $Z$ rather than $t$. 